\title{
A Single- and Three-Phase Grid Compatible Converter for Electric Vehicle (EV) On-Board Chargers
}

\author{
Hui Zhao, Member, IEEE, Yanfeng Shen, Member, IEEE, Wucheng Ying, Saikat Subhra Ghosh, Student Member, \\ IEEE, Md Rishad Ahmed, Member, IEEE, and Teng Long, Member, IEEE
}

\begin{abstract}
This paper proposes a voltage-source converter for an on-board Electric Vehicle (EV) charger which is compatible with both the single- and three-phase (1- $\phi$ and 3- $\phi$ ) grids. The classic 3$\phi$ active AC-DC rectifier circuit is used for both the 1- $\phi$ and 3- $\phi$ connection, but a new control scheme and $L C L$ filter are designed to address the double-line frequency power pulsation issue caused by a 1- $\phi$ grid without using bulky DC capacitors. The third leg of the circuit is utilized to control the power pulsation in conjunction with stored energy in the $L C L$ filter between the grid and charger rectifier. Neither additional active nor passive components are required. For the 3- $\phi$ connection, the rectifier is under balanced operation; when connected with the 1- $\phi$ grid, all three legs are controlled cooperatively as a 3- $\phi$ rectifier but under unbalanced operation to recreate the $1-\phi$ voltage. Hence advantages from the 3- $\phi$ rectifier such as space vector pulse width modulation (SVPWM) and $Y / \Delta$ transformation can be utilized to increase utilization of DC-link voltage and filter capacitance respectively. The operation principle, control, and $L C L$ filter design are reported and validated by both simulation and experiments of a 3kW porotype.
\end{abstract}

Index Terms- 1- $\phi$ and 3- $\phi$ compatible rectifier, EV battery onboard charger, double-line frequency power pulsation, power decoupling. ${ }^{1}$

\section{INTRODUCTION}

The on-board charger (OBC) for Electric vehicles (EVs) is attracting increasing attention [1-4] because of a rapid uptake of transport electrification $[5,6]$. Major automobile production and consumption countries such as the U.S. and the U.K. have set ambitious EV development roadmaps in which the OBC has been defined as an important aspect [7,8]. By 2035, the gravimetric and volumetric power densities of the $\mathrm{OBC}$ are expected to achieve $50 \mathrm{~kW} / \mathrm{kg}$ and $60 \mathrm{~kW} / \mathrm{L}$ according to the roadmap, which are approximately seven times higher than existing products [8].

The Level 2 charging in which an AC supply with the current up to $60 \mathrm{~A}$ is fed has been commonly considered as a mandatory requirement for $\mathrm{OBCs}$ in the domestic and street-side charging $[9,10]$. The voltage of such AC supplies can be either singlephase $(1-\phi)$ or three-phase $(3-\phi)$. In fact, without additional

This work was supported by Innovate UK (TS/R016968/1). (Corresponding author: Teng Long.)

H. Zhao, Y. Shen, W. Ying, S. S. Ghosh and T. Long are with the Department of Engineering, University of Cambridge, Cambridge CB3 0FA, U.K. (e-mail: hz352@cam.ac.uk; ys523@cam.ac.uk; wy256@cam.ac.uk,ssg39@cam.ac.uk,t1322@cam.ac.uk).

M. R. Ahmed is with the Dynex Semiconductor, Lincoln LN6 3LF, U.K. (email: rishadahmed@yahoo.com). upgrade on circuit breakers, 3- $\phi$ supplies can effectively increase the charging rate by three times, showing a sensible and affordable solution for EV charging. The 3- $\phi$ supply is commonly available in premises and thus it is commercially valuable to equip the EV OBCs with both $1-\phi$ and $3-\phi$ grid connections $[11,12]$. Yet most of commercial OBCs are only compatible with a 1- $\phi$ supply and it is hardly seen literature on combined 1- $\phi$ and 3- $\phi$ OBCs. The potentials of such technology and solution have been overlooked by both the industry and academia.

However, the difference and challenge of combining singleand 3- $\phi$ OBCs are beyond only adding one more leg in the AC$\mathrm{DC}$ rectifier of the $\mathrm{OBC}$. When the $\mathrm{OBC}$ is connected to a $1-\phi$ supply, a large power pulsation at double line frequency [13] is generated at the AC-DC rectifier, which would not appear when connecting to a 3- $\phi$ supply. In this paper, the AC-DC rectifier of the OBC as shown in Fig. 1 is focused to enable both singleand 3- $\phi$ OBC connection and achieve high power density.

TABLE I summarizes the techniques dealing with this double-line frequency power pulsation. Conventional techniques usually employ a bulk DC capacitor bank to reduce the voltage pulsation at the DC link of the rectifier. The power density is low due to the large number of capacitors at the DC-

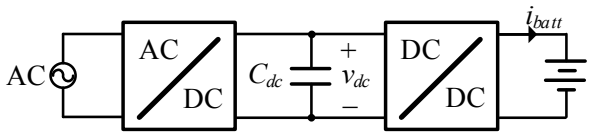

Fig. 1. The diagram for EV chargers with a 1- $\phi$ grid.

TABLE I

COMPARISON AMONG DIFFERENT TECHNIQUES TO RESOLVE THE DOUBLE-LINE FREQUENCY POWER PULSATION

\begin{tabular}{|c|c|c|c|}
\hline Method & $\begin{array}{l}\text { DC link } \\
\text { voltage }\end{array}$ & $\begin{array}{l}\text { Charging } \\
\text { current }\end{array}$ & Main issues \\
\hline $\begin{array}{c}\mathrm{DC} \\
\text { capacitor } \\
\text { storage }\end{array}$ & $d c_{A}$ & & Large DC capacitor \\
\hline $\begin{array}{l}\text { Fluctuate } \\
\text { charging } \\
\text { current }\end{array}$ & & & Impairing battery \\
\hline $\begin{array}{c}\text { Variable } \\
\text { DC voltage }\end{array}$ & & & $\begin{array}{l}\text { High voltage stress; } \\
\text { Over modulation }\end{array}$ \\
\hline $\begin{array}{c}\text { Active } \\
\text { power filter } \\
\text { (APF) }\end{array}$ & & & $\begin{array}{l}\text { Extra switching } \\
\text { devices for control; } \\
\text { Extra passive devices } \\
\text { for energy storage }\end{array}$ \\
\hline
\end{tabular}


link. The reliability is also limited because the use of less reliable electrolytic capacitors is usually inevitable in this technique to achieve large capacitance.

To increase the power density, [14] boldly directs the low frequency power pulsation into the batteries so the capacitance of the DC-link can be significantly reduced but the DC current provided by the $\mathrm{OBC}$ contains a large $\mathrm{AC}$ ripple at the doubleline frequency although the impact of the low frequency ripple current at to the batter is unclear. Some literature $[15,16]$ shows that the current pulsation will cause an adverse impact on the battery[17] such as the temperature increase, the capacity degradation, and the gassing.

Advanced control techniques can eliminate the current distortion caused by the double-line frequency power pulsation. [18] employs a repetitive algorithm and a feed-forward controller to eliminate the output current distortion. [19] applies a feedback controller to reduce the current pulsation. However, those special control techniques are based on using the inconstant DC-link voltage largely pulsating at the double-line frequency to smooth the output DC current and a high control bandwidth must be employed. The pulsating DC voltage will cause voltage stress and over-modulation of semiconductors at the peak and bottom of the pulsation respectively.

The active power filter (APF) can divert and store the doubleline frequency power pulsation by using much smaller energy storage components. There are different APF circuit topologies depending on the location of the APF and the type of components used for energy storage in the APF [13, 19-30]. The APF can be implemented at the DC side [24, 25, 27] as shown in Fig. 2 (a) or AC side as shown in Fig. 2 (b) [13, 29, 31]; there are inductor-based APFs [24] and capacitor-based APFs $[13,20,21,27]$. To identify the optimal location and the type of the energy storage components used in APFs, the unified equations among these techniques are necessary.

Reducing the cost and size of the APFs are important. [20] uses split-capacitors to control the current in both the rectifier and APF, and thus no extra switches are required. However, extra passive components are still needed to store the pulsating power. [30, 32] use novel topologies to reduce the capacitance but the voltage ratings of the capacitors and the semiconductor devices must be increased. Since the passive components storing the pulsating energy can dominate the volume and weight of the APF, it is important to investigate the volume/weight of the energy storage components.

This paper proposes a universal converter which is compatible with both a 1- $\phi$ and 3- $\phi$ supplies. Unlike some other chargers $[11,12]$ in which the third leg of the rectifier is redundant when connected to a 1- $\phi$ supply, the proposed technique utilizes the third leg as part of the AC side APF to address the double-line frequency power pulsation issue while the other two legs are connected to the 1- $\phi$ AC supply. Furthermore, the low frequency power pulsation is diverted into the $L C L$ filter between grid and converter and the capacitor at the $L C L$ filter is used to store the power pulsation. Therefore, neither extra semiconductor nor passive components are required. From control's perspective, unlike the conventional APF technique, which decouples and separately controls the dc

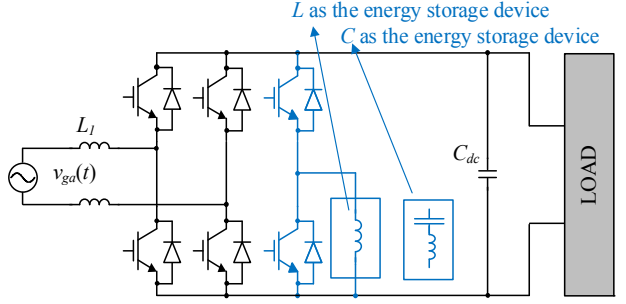

(a)

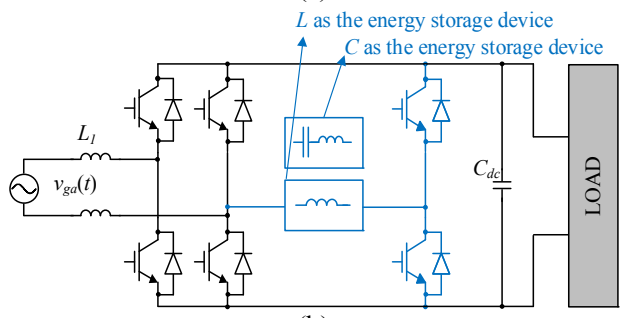

(b)

Fig. 2. The circuits of typical APFs: (a) the DC side APF, (b) the AC side APF.

power and the double-line frequency power pulsation, the proposed control operates three legs as an unbalanced converter when connected with a 1- $\phi$ supply. Therefore, some benefits from 3- $\phi$ converters can be utilized, namely, the $\mathrm{Y} / \Delta$ transformation and space vector pulse width modulation (SVPWM) can be applied to amplify the equivalent capacitance in $L C L$ filters for APF power pulsation storage and achieve higher DC voltage utilization compared with sinusoidal pulse width modulation (SPWM), respectively. When connected with a 3- $\phi$ supply, the third leg is used with the other two legs like a normal 3- $\phi$ rectifier and no APF is needed because no doubleline frequency power pulsation exists.

The paper is organized as follows: section II derives the universal equations to evaluate the optimal APF circuit. Section III proposes the circuit and discusses its operation principle. Section IV discusses the parameter design procedure of the $L C L$ filter for this combined single- and 3- $\phi$ rectifiers along with the size and weight comparison with the conventional circuit. Section V presents simulations and experiments to verify the design.

\section{Evaluations of Double Line Frequency APFs BASED ON UNIFIED EQUATIONS}

Various APFs exist to filter the double line frequency power pulsation of a 1- $\phi$ rectifier. Fig. 2 (a) and (b) show the APF at the DC side AC side respectively. Either the inductor $L$ or capacitor $C$ or both can be used at the $\mathrm{AC}$ and DC side as energy storage components. Because both the topology and type of energy storage components can affect the current / voltage waveforms so does the power density of the APF, identifying the optimal circuit is complicated. A unified expression is derived to assess the performance of the different type of APFs as well as the volume expressions for the passive components are defined to support the selection of the APF in order to minimize the size of the passive components.

\section{A. Evaluating the Size and Weight of Inductors and Capacitors as Energy Storage Devices for APFs}




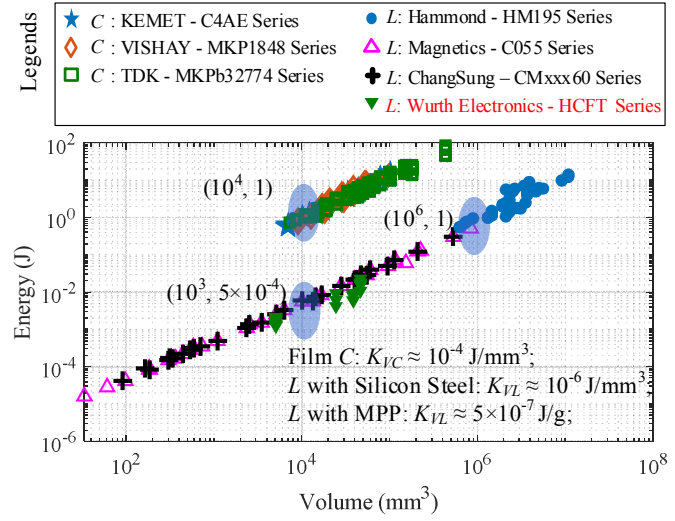

(a)

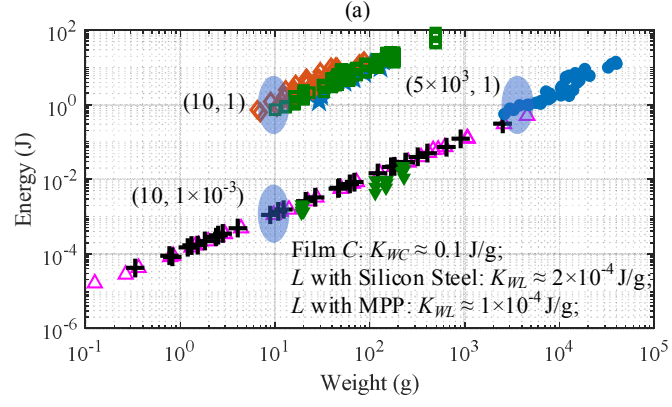

(b)

Fig. 3. The relationship between the volume/weight and the maximum energy storage for the inductors and film capacitors: (a) the energy vs the volume, and (b) the energy vs the weight.

To discuss the relationship between the volume/weight versus the maximum stored energy, Fig. 3 (a) and (b) records 241 different capacitors and 121 different inductors from the market, including 49 inductors with silicon steel cores from the Hammond Manufacturing [33], 36 inductors with MPP power cores from the Magnetics Inc[34], 36 inductors with MPP power cores from ChangSung Corp [35], 19 inductor from Wurth Electronics's HCFT series, 53 film capacitors from KEMET [36], 49 film capacitors from Vishay [37], and 139 film capacitors from TDK [38]. It should be noted that the weight information of 39 capacitors from C4AE series is not available in the datasheets so the Energy v.s Weight relationship shown in Fig. 3 (b) contains 199 capacitors while Fig. 3 (a) contains all 238 capacitors to illustrate the Energy v.s Volume relationship. Moreover, to calculate the size and volume of inductors with MPP cores, the maximum magnetic flux density is set as $0.1 \mathrm{~T}$ and the fill factor $=0.4$ is used as a typical value suggested in Magnetics Inc's design guides [39] in toroidal cores. The commercial inductors have two current limits: the saturation current (donated by $I_{\text {sat }}$ ), the current for temperature rise (donated by $I_{r m s}$ ). When evaluating the maximum energy storage capability, the rated current (donated by $I_{\text {rated }}$ ) is employed, which is the minimum value of $I_{s a t}$ and $I_{r m s}$, so that both the saturation constraints and the temperature constraints, are considered in Fig. 3.

Fig. 3 shows that, although the size/weight difference with different manufacturers/series, the volume/weight of both the inductors and capacitors are approximately linear with their maximum energy storage. This linear relation can be expressed as (1) and (2) for inductors and capacitors:

$$
\begin{aligned}
& \left\{\begin{array}{l}
\text { Eng }_{L}=\frac{1}{2} L I_{\text {rated }}^{2}=K_{V L} \cdot V O L_{L} \\
\text { Eng }_{L}=\frac{1}{2} L I_{\text {rated }}^{2}=K_{W L} \cdot W E T_{L}
\end{array}\right. \\
& \left\{\begin{array}{l}
\text { Eng }_{C}=\frac{1}{2} C V_{\text {rated }}^{2}=K_{V C} \cdot V O L_{C} \\
\text { Eng }_{C}=\frac{1}{2} C V_{\text {rated }}^{2}=K_{W C} \cdot W E T_{C}
\end{array}\right.
\end{aligned}
$$

where $E n g_{L} / E n g_{C}$ is the maximum energy which can be stored in the $L / C ; I_{\text {rated }} / V_{\text {rated }}$ is the rated maximum current/voltage, $V O L_{L} / W E T_{L}$, and $V O L_{C} / W E T_{C}$ are the volume/weight of the inductor and capacitors, $K_{V L} / K_{W L}$ and $K_{V C} / K_{W C}$ the energy density coefficients per unit volume/weight for inductors and capacitors.

Large energy density coefficients can result in small volume/weight. In Fig. 3, all the energy density coefficients can be obtained by choosing a specific point (as highlighted with blue in Fig. 3). For film capacitors, $K_{V C} \approx 10^{-4} \mathrm{~J} / \mathrm{mm}^{3}$, and $K_{W C}$ $\approx 0.1 \mathrm{~J} / \mathrm{g}$; for silicon steel inductors, $K_{V L} \approx 10^{-6} \mathrm{~J} / \mathrm{mm}^{3}$, and $K_{W L}$ $\approx 2 \times 10^{-4} \mathrm{~J} / \mathrm{g}$; for inductors with MPP cores, $K_{V L} \approx 5 \times 10^{-7} \mathrm{~J} / \mathrm{mm}^{3}$, and $K_{W L} \approx 1 \times 10^{-4} \mathrm{~J} / \mathrm{g}$.

\section{B. Unified Voltage and Current Equations of APF at the DC and AC Sides}

To derive the equation, an inductor is used for storing energy at the DC side APF as shown in Fig. 2 (a). The double-line frequency (notated as subscript 100 as the line frequency is considered as $50 \mathrm{~Hz}$ ) power pulsation $p_{100}(t)=P_{100} \sin \left(2 \omega_{g} t+\theta\right)$ needs to satisfy:

$$
v_{l}(t) i_{l}(t)=L \frac{d i_{l}(t)}{d t} i_{l}(t)=P_{100} \sin \left(2 \omega_{g} t+\theta\right)
$$

where the $i_{l}(t)$ and $v_{l}(t)$ are the inductor current and voltage respectively; $L$ is the inductor; $\omega_{g}$ and $\theta$ are the grid's angular frequency and phase angle respectively, $p_{100}(t)$ is the double line frequency power pulsation, and $P_{100}$ is its magnitude.

The solution of (3) is (4),

$$
\left\{\begin{array}{l}
i_{l}(t)= \pm \sqrt{\frac{P_{100}}{\omega_{g} L}} \sqrt{\left(K-\cos \left(2 \omega_{g} t+\theta\right)\right)} \\
v_{l}(t)= \pm \sqrt{P_{100} \omega_{g} L} \frac{\sin \left(2 \omega_{g} t+\theta\right)}{\sqrt{\left(K-\cos \left(2 \omega_{g} t+\theta\right)\right)}}
\end{array}\right.
$$

where $K$ is the constant in general solutions of the differential equations, determined by $i_{l}(0)$ as: $K=i_{l}(0) \frac{\omega_{g} L}{P_{100}}+\cos (\theta)$. Because $i_{l}(0)$ can be controlled by setting specific value, $K$ is determined by the control strategy. $i_{l}(t)$ must be a real number so $K \geq 1$ is required. Specially, when $K=1$, (4) can be further simplified as, 


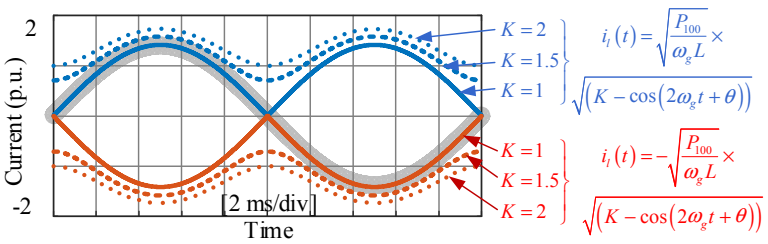

(a)
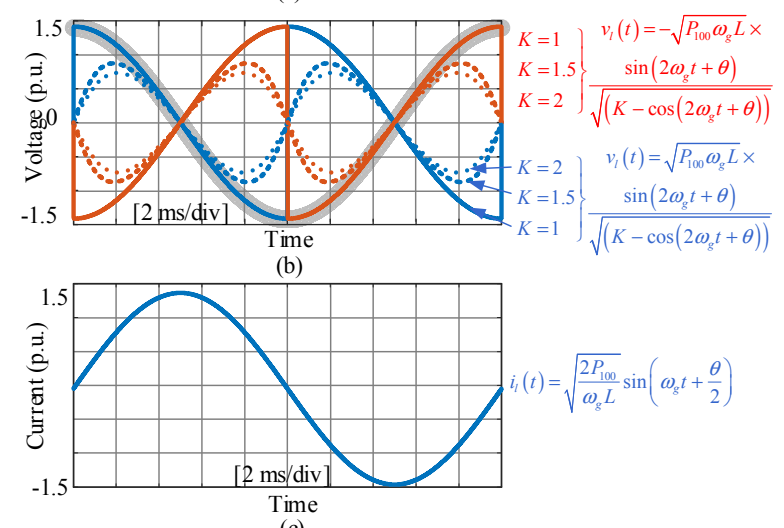

(c)

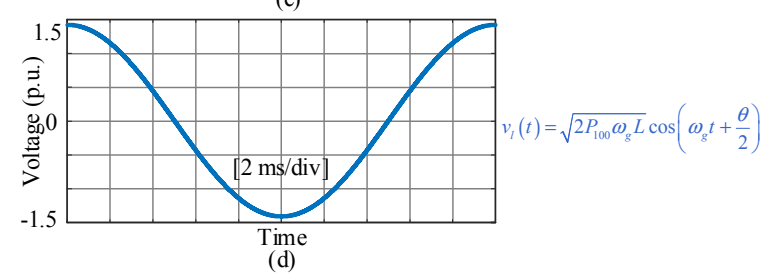

Fig. 4. The waveforms for inductors as energy storage components: (a) $i_{l}(t)$ in the DC side APF, (b) $v_{l}(t)$ in the DC side APF, (c) $i_{l}(t)$ in the AC side APF, and (d) $v_{l}(t)$ in the AC side APF.

$$
\left\{\begin{array}{l}
i_{l}(t)= \pm \sqrt{\frac{2 P_{100}}{\omega_{g} L}} \sin \left(\omega_{g} t+\frac{\theta}{2}\right) \\
v_{l}(t)= \pm \sqrt{2 P_{100} \omega_{g} L} \cos \left(\omega_{g} t+\frac{\theta}{2}\right)
\end{array}\right.
$$

Fig. 4(a) and (b) show the waveforms of $i_{l}(t)$ and $v_{l}(t)$ at different $K$ for the DC side APF. When $K \geq 1$, the DC offset of the inductor current occurs and both the mean and peak values increase when $K$ increases. As shown in Fig. 4(a)-(b), the blue/red curves represent the positive/negative solutions in (4). When $K=1$, the shape of the $i_{l}(t)$ is sinusoidal within both [0, $10] \mathrm{ms}$ and $[10,20] \mathrm{ms}$ as the grey curves, but $i_{l}(t)$ flips over at the communication point when $t=10 \mathrm{~ms}$ so its polarity remains unchanged. This flip-over of $i_{l}(t)$ will flip $v_{l}(t)$ because $v_{l}(t)=$ $L \mathrm{~d} i_{l}(t) / \mathrm{d} t$.

If $L$ is installed at the $\mathrm{AC}$ side, the equation to compensate $P_{100}$ is as same as (3) and the solution remains as same as (4). However, the value $K$ can only be 1 because the $i_{l}(t)$ of the AC side APF needs a natural commutation point to change the polarity and there is no DC offset. Therefore, $K=1$ is mandatory. $i_{l}(t)$ and $v_{l}(t)$ are shown in Fig. 4 (c) and (d). From existing literature, (4) has been verified by both DC side APFs in $[27,40]$ and AC side APFs in [13].

\section{Volume/Weight Expressions of Passive Components}

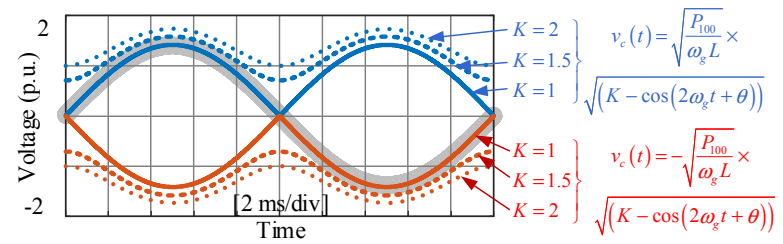

(a)
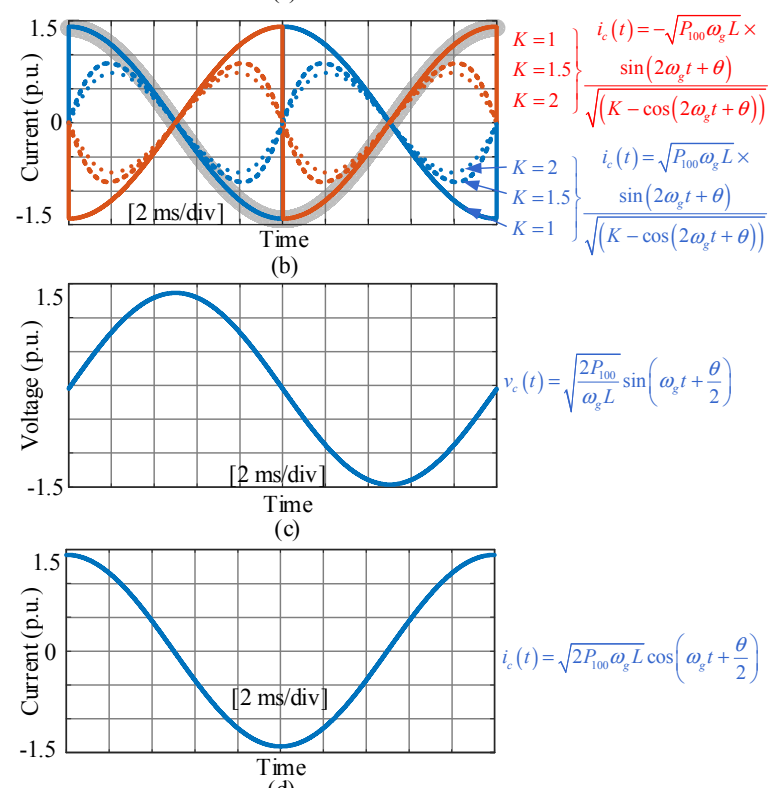

(d)

Fig. 5. The waveforms for capacitors as energy storage components: (a) $i_{l}(t)$ in the DC side APF, (b) $v_{l}(t)$ in the DC side APF, (c) $i_{l}(t)$ in the AC side APF, and (d) $v_{l}(t)$ in the AC side APF.

Based on the unified solution in (4), the magnitude of $i_{l}(t)$ for AC side APF and DC side APF has the same expression as shown in (6).

$$
\operatorname{mag}\left(i_{l}(t)\right)=\sqrt{P_{100} /\left(\omega_{g} L\right)} \sqrt{(K+1)}
$$

From (6), it is obvious that the AC side inductor current equals to the smallest value of that in the DC side APF for storing the same amount of energy, i.e. $K=1$. The inductance $L$ and inductor current $i_{l}(t)$ determine the volume of inductors.

Substituting (6) into (1) yields (7):

$$
\left\{\begin{array}{l}
V O L_{L}=\left(\frac{1}{2} L I_{\text {rated }}^{2}\right) / K_{V L}=\frac{P_{100}}{2 \omega_{g} K_{V L}}(K+1) \\
W E T_{L}=\left(\frac{1}{2} L I_{\text {rated }}^{2}\right) / K_{W L}=\frac{P_{100}}{2 \omega_{g} K_{W L}}(K+1)
\end{array}\right.
$$

Eq. (7) shows that the volume/weight of the required inductance is determined by the power pulsation $\left(P_{100}\right)$, the material $\left(K_{V L} / K_{W L}\right)$, and the control stratagem (i.e. the value of $K)$ from (6).

When a capacitor is applied as the energy storage device, similar to the derivation of using the inductor, the double-line power pulsation needs to satisfy (8), where $v_{c}$ and $i_{c}$ are the voltage and current of the capacitor used in APF respectively. The general solutions of (8) are given in (9) and the volume expressions are in (10). As aforementioned, the solution and 
volume expressions of capacitor based APF in (8) and (9) are applicable for both the AC and DC side APFs. For DC side APF, $K \geq 1$. For AC side APF, $K=1$. The voltage and current waveforms of the capacitor at the DC and AC side APF are shown in Fig. 5.

$$
\begin{gathered}
v_{c}(t) i_{c}(t)=v_{c}(t) C \frac{d v_{c}(t)}{d t}=P_{100} \sin \left(2 \omega_{g} t+\theta\right) \\
v_{c}(t)= \pm \sqrt{\frac{P_{100}}{\omega_{g} C}} \sqrt{K-\cos \left(2 \omega_{g} t+\theta\right)} \\
i_{c}(t)= \pm \sqrt{\frac{P_{100}}{\omega_{g} C}} \frac{\sin \left(2 \omega_{g} t+\theta\right)}{\sqrt{\left(K-\cos \left(2 \omega_{g} t+\theta\right)\right)}} \\
\left\{\begin{array}{l}
\operatorname{mag}\left(v_{c}(t)\right)=\sqrt{\frac{P_{100}}{\omega_{g} C}} \sqrt{K+1} \\
\operatorname{VOL}_{C}=\left(\frac{1}{2} C V_{\text {rated }}^{2}\right) / K_{V C}=\frac{P_{100}}{2 \omega_{g} K_{V C}}(K+1) \\
\operatorname{WET}_{C}=\left(\frac{1}{2} C V_{\text {rated }}^{2}\right) / K_{W C}=\frac{P_{100}}{2 \omega_{g} K_{W C}}(K+1)
\end{array}\right.
\end{gathered}
$$

where $V O L_{C} / W E T_{C}$ is the volume/weight of the capacitor, and $K_{V C} / K_{W C}$ is the energy density per unit volume/weight.

Because (10) has the same form to (7), one unified equation can be used to assess the volume and weight of the APF passive components, which depends on the location of the APF in terms of the value $K$ and the type of the passive components in terms of the value of $K_{L}$ and $K_{C}$.

\section{Optimal Circuit Selection}

From Fig. 5, it is obvious that the capacitor shows higher energy density than inductors considering both the size and weight, i.e. $K_{V C} \gg K_{V L}$ and $K_{W C} \gg K_{W L}$, so the APF is in favour of using film capacitors for storing energy. However, as shown in Fig. 2, the voltage source APF with a capacitor needs an extra inductor for ripple current damping and limiting, which needs to be considered in the design.

Existing techniques $[25,30,41]$ use capacitance per watt (F/W) to identify the optimal circuit, and propose the APFs with small capacitance but a high voltage rating. However, the volume/weight of capacitors in different types of APFs have not been compared. The unified volume expression in (10) can be used to identify the circuit with optimal volume and weight.

In (10), $P_{100}, \omega_{g} . K_{M}$ are constant, and the only controllable parameter is $K$. To achieve the minimum volume, $K=1$ should be selected no matter AC side or DC side APFs. However, when $K=1$ of the DC side APF, the control variables, capacitor current and voltage $i_{c}(t)$ and $v_{c}(t)$, are non-sinusoidal with sharp changes as shown in Fig. 4 and Fig. 5. The widely spread spectrums of the voltage and current require a high control bandwidth to be implemented at the APF and the filtering performance is inevitably compromised [27]. Furthermore, the parasitic components might dominate the high-frequency impedance, resulting in errors of the instantaneous power equation in (3).

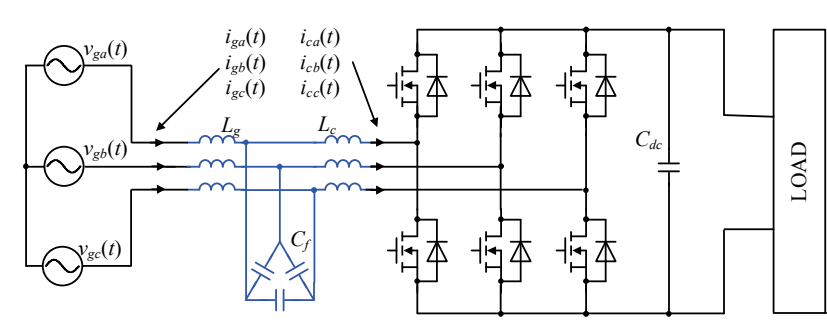

(a)

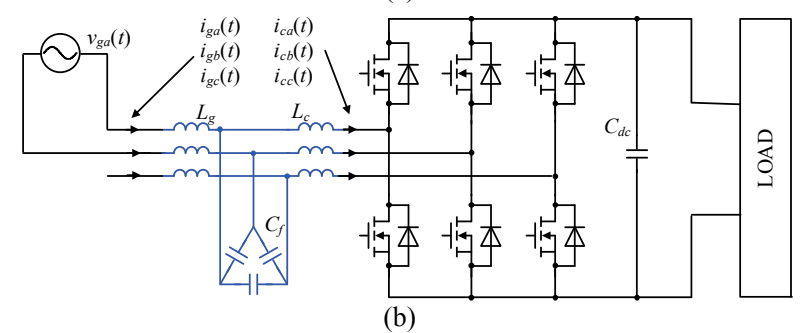

Fig. 6. The proposed universal converter operates (a) with a 3- $\phi$ grid, and (b) with a 1- $\phi$ grid.

Instead, $K$ must be 1 when the AC side APF and both the voltage and current are sinusoidal. The control of side APF is much easier than the DC counterpart for the same power density of the APF so the filtering performance of the APF at the AC side is better.

In conclusion, the APF using capacitors at the AC side has the advantages of low volume, low bandwidth control requirements, high filtering performance and robustness with parasitic parameters thus it has been selected in this paper.

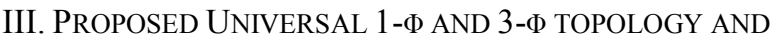 CONTROL FOR AC-DC RECTIFIER USED IN OBCS}

The proposed universal 1- $\phi$ and the 3- $\phi$ circuit is as shown in Fig. 6. When connected with a 1- $\phi$ supply, the third leg of the rectifier can be utilized to control the power flow to compensate the double-line frequency power pulsation, therefore no extra power electronic switches are required for the APF functionality. Moreover, the $L C L$ filter between the supply and the converter can be utilized as energy storage components thus no extra passive components are required. Because the $L C L$ filter inherently has inductors, no additional ripple current damping inductors are required in the APF.

The $L C L$ filter in Fig. 6 is highlighted in blue to emphases that it not only attenuates the switching harmonics but also stores the unbalanced power pulsation when used as part of the APF for a 1- $\phi$ connection.

\section{A. Double-Line Frequency Power Pulsation in Form of Sequence Networks}

The instantaneous power $p(t)$ can be written in the form of sequence network, where the subscripts $0,1,2$ donate the zero sequence, positive sequence, and negative sequence respectively. If no zero-sequence current exists, the expression of $p(t)$ is shown as (11): 
IEEE POWER ELECTRONICS REGULAR PAPER

TABLE II

THE DC POWER AND 100HZ POWER RIPPLE FROM THE SEQUENCE NETWORK

$$
\begin{aligned}
& \begin{array}{llll}
\hline \hline V & I & P(\mathrm{dc}) & \dot{P}_{100}(@ 100 \mathrm{~Hz}) \\
\hline
\end{array} \\
& 1 \quad 1 \quad \frac{3}{2} V_{1} I_{1} \cos \left(\theta_{v 1}-\theta_{i 1}\right) \quad 0 \\
& 22 \frac{3}{2} V_{2} I_{2} \cos \left(\theta_{v 2}-\theta_{i 2}\right) \quad 0 \\
& 21 \quad 0 \quad-j \frac{3}{2} \dot{V}_{2} \dot{I}_{1} \\
& 12 \quad 0 \quad-j \frac{3}{2} \dot{V}_{1} \dot{I}_{2} \\
& \begin{array}{llll}
0 & 1 & 0 & 0 \\
0 & 2 & 0 & 0 \\
\hline
\end{array} \\
& \begin{aligned}
p(t)= & {\left[\begin{array}{l}
v_{a}(t) \\
v_{b}(t) \\
v_{c}(t)
\end{array}\right]^{T}\left[\begin{array}{l}
i_{a}(t) \\
i_{b}(t) \\
i_{c}(t)
\end{array}\right] } \\
= & V_{0}(t)^{T} I_{1}(t)+V_{0}(t)^{T} I_{2}(t)+V_{1}(t)^{T} I_{1}(t)+V_{1}(t)^{T} I_{2}(t) \\
& +V_{2}(t)^{T} I_{1}(t)+V_{2}(t)^{T} I_{2}(t)
\end{aligned}
\end{aligned}
$$

There are six components in (11), and their contributions can be summarized in TABLE II. TABLE II shows that $p_{100}$ is generated by coupling the positive and negative sequence. When connected with a balanced 3- $\phi$ supply, no negativesequence voltage and current exist so $p_{100}$ is zero.

A 1- $\phi$ supply can be considered as an unbalanced 3- $\phi$ supply, whereas the 3- $\phi$ voltages and the 3- $\phi$ currents are as (12):

$$
\left\{\begin{array}{l}
{\left[\dot{V}_{g a}, \dot{V}_{g b}, \dot{V}_{g c}\right]=\left[\dot{V}_{g}, 0,0\right]} \\
{\left[\dot{I}_{g a}, \dot{I}_{g b}, \dot{I_{g c}}\right]=\left[\dot{I}_{g},-\dot{I}_{g}, 0\right]}
\end{array}\right.
$$

By using the abc/zpn transformation, the voltages and currents in the sequence network can be expressed as (13):

$$
\left\{\begin{array}{l}
{\left[\dot{V}_{g 0}, \dot{V_{g 1}}, \dot{V_{g 2}}\right]=T_{a b c 2 z p n}\left[\dot{V}_{g a}, \dot{V}_{g b}, \dot{V_{g c}}\right]=\frac{1}{3} \dot{V}_{g}[1,1,1]} \\
{\left[\dot{I}_{g 0}, \dot{I_{g 1}}, \dot{I_{g 2}}\right]=T_{a b c 2 z p n}\left[\dot{I_{g a}}, \dot{I_{g b}}, \dot{I_{g c}}\right]=\frac{1}{\sqrt{3}} \dot{I}_{g}\left[0,1 \angle-30^{\circ}, 1 \angle 30^{\circ}\right]}
\end{array}\right.
$$

where $T_{a b c 2 z p n}=\frac{1}{3}\left[\begin{array}{ccc}1 & 1 & 1 \\ 1 & \alpha & \alpha^{2} \\ 1 & \alpha^{2} & \alpha\end{array}\right]$ is the matrix to compute the sequence components (positive, negative, and zero) from 3- $\phi$ abc system, and $\alpha=1 \angle-30^{\circ}$ is the complex operator for the $2 \pi / 3$ rotation.

Substituting (13) into TABLE II derives (14) which is the expression of $\dot{P}_{100-r g}$ (the phasor of the double-line frequency power pulsation generated by the grid) in form of sequence network:

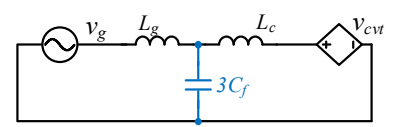

(a)

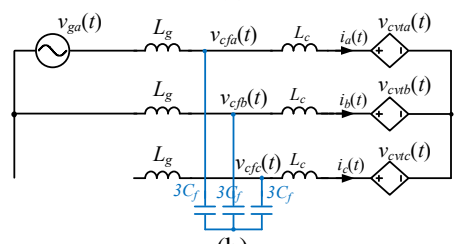

(b)

Fig. 7. The equivalent circuits with a $3-\phi$ and $1-\phi$ grid: (a) the 1- $\phi$ equivalent circuit with a $3-\phi$ grid, and (b) the equivalent circuit with a 1- $\phi$ grid.

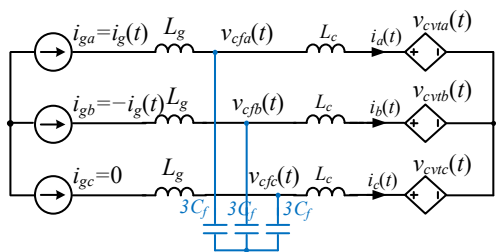

(a)

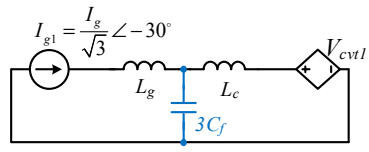

(b)

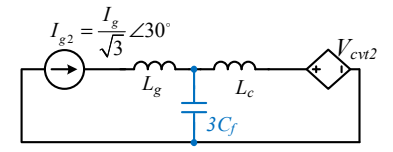

(c)
Fig. 8. The equivalent circuits with a 1- $\phi$ grid: (a) the equivalent circuit with current sources, (b) positive-sequence equivalent circuit, and (c) negative sequence equivalent circuit.

$$
\begin{aligned}
& \dot{P}_{100-v g}=-j \frac{3}{2} \dot{V}_{g 2} \dot{I}_{g 1}-j \frac{3}{2} \dot{V}_{g 1} \dot{I}_{g 2} \\
& =-j \frac{3}{2}\left(\frac{1}{3} \dot{V}_{g}\right)\left(\frac{1}{\sqrt{3}} \dot{I}_{g} \angle-30^{\circ}\right)-j \frac{3}{2}\left(\frac{1}{3} \dot{V}_{g}\right)\left(\frac{1}{\sqrt{3}} \dot{I}_{g} \angle 30^{\circ}\right) \\
& =-j \frac{1}{2} \dot{V}_{g} \dot{I}_{g}
\end{aligned}
$$

\section{B. Operating Principles}

As concluded in Section II, the AC side APF with capacitors is preferred. The $\mathrm{Y} / \Delta$ transformation can amplify the equivalent capacitance provided by the $L C L$ filter.

When connected with a 3- $\phi$ supply as shown in Fig. 6 (a), the $3-\phi s$ of the converter are balanced. A 1- $\phi$ equivalent circuit is shown in Fig. 7 (a). Because $p_{100}=0$, there is no double-line frequency power pulsation. The voltage phasor of the rectifier is controlled as $\dot{V}_{c v t}=\dot{V}_{g}+j \omega_{g}\left(L_{g}+L_{c}\right) \dot{I}_{g}$. The subscript $c v t$ donates the voltage generated by the converter (rectifier).

When connected with a 1- $\phi$ supply as shown in Fig. 6 (b), the equivalent circuit is shown in Fig. 7 (b) where $v_{c v t a}, v_{c v t b}$, and $v_{c v t c}$ are the 3- $\phi$ voltages of the converter, and $v_{c f a}, v_{c f b}$ and $v_{c f c}$ are the 3- $\phi$ voltages across the $C_{f}$. Both the power supply and impedance are asymmetrical, and the circuit needs to be simplified. By using the superposition theory, the unconnected terminal (Phase-C) is substituted by a current source with the current as zero, i.e. $i_{g c}=0$. The Phase-A and Phase-B form the line and neutral of the 1- $\phi$ where the current is $i_{g}$ and $-i_{g}$ respectively as shown in Fig. 8 (a). The sequence network circuits in terms of the forward and backward sequence are 


\section{IEEE POWER ELECTRONICS REGULAR PAPER}

shown in Fig. 8 (b) and (c) where the positive sequence current is $\dot{I}_{g 1}$ and the negative sequence current is $\dot{I}_{g 2}$. The controlled voltage of the rectifier at each phase ( $v_{c v t a}, v_{c v t b}$, and $\left.v_{c v t c}\right)$ can be expressed in the positive sequence (i.e. $\dot{V}_{c v t 1}$ ) and the negative sequence (i.e. $\dot{V}_{c v t 2}$ ) as shown in Fig. 8 (b) and (c).

Two requirements need to be satisfied: 1) the $\dot{I}_{g}$ needs to be controlled as (15), and 2) the capacitor $C_{f}$ should store all double-line frequency power pulsation generated by the grid, $\dot{P}_{100-C f}=\dot{P}_{100-v g}$ as (16).

$$
\left\{\begin{array}{l}
\dot{V}_{g}-\left(\dot{V}_{c f a}-\dot{V}_{c f b}\right)=j \omega_{g} 2 L_{g} \dot{I}_{g} \\
\dot{P}_{100-C f}=\dot{P}_{100-V g}
\end{array}\right.
$$

where $\dot{P}_{100-C f}$ and $\dot{P}_{100-v g}$ are the double-line frequency power generated by capacitors and the grid respectively.

The $\dot{P}_{100-C f}$ is derived as (17) from TABLE II:

$$
\begin{aligned}
& \dot{P}_{100-C f}=-j \frac{3}{2} \dot{V}_{c f 2} \dot{I}_{c f 1}-j \frac{3}{2} \dot{V}_{c f 1} \dot{I}_{c f 2} \\
& =-j \frac{3}{2}\left(\begin{array}{l}
\dot{V}_{c f 1} j \omega_{g}\left(3 C_{f}\right) \dot{V}_{c f 2} \\
+\dot{V}_{c f 2} j \omega_{g}\left(3 C_{f}\right) \dot{V}_{c f 1}
\end{array}\right) \\
& =9 \omega_{g} C_{f} \dot{V}_{c f 1} \dot{V}_{c f 2}
\end{aligned}
$$

Substituting $\left[\begin{array}{l}\dot{V}_{c f a} \\ \dot{V}_{c f b}\end{array}\right]=\left[\begin{array}{lll}1 & 1 & 1 \\ 1 & \alpha^{2} & \alpha\end{array}\right]\left[\begin{array}{l}\dot{V}_{c f 0} \\ \dot{V}_{c f 1} \\ \dot{V}_{c f 2}\end{array}\right]$ into (15) derives (18),

and substituting (17) into (16) derives (19). Consequently, the two requirements are transformed in the form of sequence network:

$$
\left\{\begin{array}{l}
\left(1 \angle 30^{\circ}\right) \dot{V}_{c f 1}+\left(1 \angle-30^{\circ}\right) \dot{V}_{c f 2}=\frac{1}{\sqrt{3}} \dot{V}_{R E C} \\
\dot{V}_{c f 1} \dot{V}_{c f 2}=\frac{1}{9 \omega_{g} C_{f}} \dot{P}_{100-v g}=\frac{-j}{18 \omega_{g} C_{f}} \dot{V}_{g} \dot{I}_{g}
\end{array}\right.
$$

where $\dot{V}_{R E C}=\dot{V}_{g}-j \omega_{g} 2 L_{g} \dot{I}_{g}$ is a defined vector.

There are two variables ( $\dot{V}_{c f 1}$ and $\dot{V}_{c f 2}$ ) in the two equations,(18) and (19). The solution can be derived as (20):

$$
\left\{\begin{array}{l}
\dot{V}_{c f 1}=\left(\frac{1}{\sqrt{3}} \dot{V}_{R E C} \pm \dot{\Lambda}\right)\left(\frac{1}{2} \angle-30^{\circ}\right) \\
\dot{V}_{c f 2}=\left(\frac{1}{\sqrt{3}} \dot{V}_{R E C} \mp \dot{\Lambda}\right)\left(\frac{1}{2} \angle 30^{\circ}\right)
\end{array}\right.
$$

where $\dot{\Lambda}=\sqrt{\frac{\dot{V}_{R E C}^{2}}{3}-\frac{4 \dot{P}_{100-v g}}{9 \omega_{g} C_{f}}}$ is a defined vector.
From Fig. 8 (b) and (c), the rectifier voltage in the positive and negative sequences need to be controlled as:

$$
\begin{aligned}
& \left\{\begin{array}{l}
\dot{V}_{c v t 1}=\dot{V}_{c f 1}+\left(\dot{V}_{c f 1} j \omega_{g}\left(3 C_{f}\right)-\frac{\dot{I}_{g}}{\sqrt{3}} \angle-30^{\circ}\right) j \omega_{g} L_{c} \\
\dot{V}_{c v t 2}=\dot{V}_{c f 2}+\left(\dot{V}_{c f 2} j \omega_{g}\left(3 C_{f}\right)-\frac{\dot{I}_{g}}{\sqrt{3}} \angle 30^{\circ}\right) j \omega_{g} L_{c}
\end{array}\right.
\end{aligned}
$$

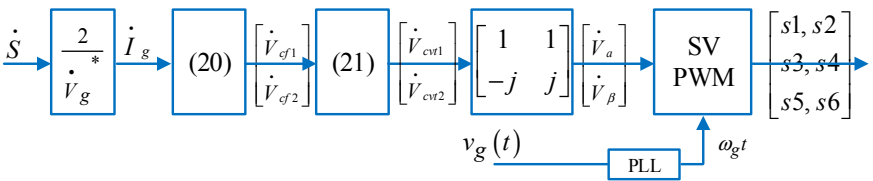

Fig. 9. The open-loop control block for the 1- $\phi$ connection.

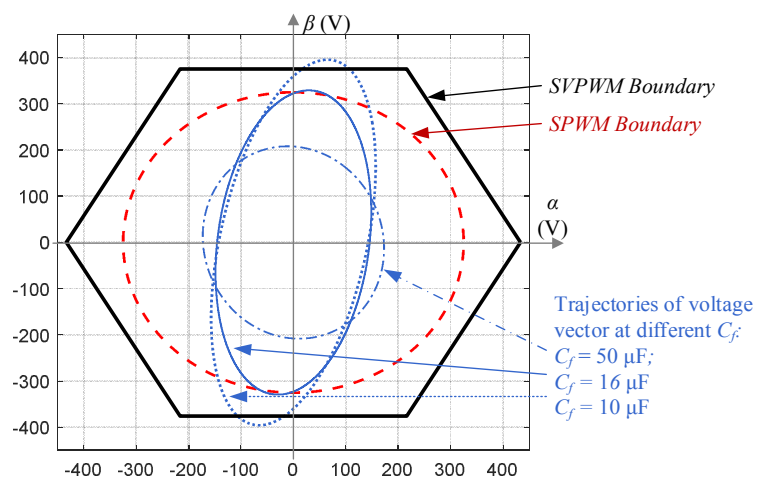

Fig. 10. The diagram of typical solution trajectories with the boundaries of both SPWM and SVPWM $\left(V_{d c}=650 \mathrm{~V}, P_{100}=3.3 \mathrm{~kW}\right)$.

In order to increase the DC voltage utilization, the SVPWM is used, in which the voltage reference in the $\alpha \beta$ axis is required as :

$$
\left[\begin{array}{l}
\dot{V}_{c v t \alpha} \\
\dot{V}_{c v t \beta}
\end{array}\right]=T_{a b c 2 \alpha \beta} T_{z p n 2 a b c}\left[\begin{array}{l}
\dot{V}_{c v t 0} \\
\dot{V}_{c v t 1} \\
\dot{V}_{c v t 2}
\end{array}\right]=\left[\begin{array}{cc}
1 & 1 \\
-j & j
\end{array}\right]\left[\begin{array}{l}
\dot{V}_{c v t 1} \\
\dot{V}_{c v t 2}
\end{array}\right]
$$

where $T_{a b c 2 \alpha \beta}=\left[\begin{array}{cc}1 & 0 \\ -\frac{1}{2} & \frac{\sqrt{3}}{2} \\ -\frac{1}{2} & -\frac{\sqrt{3}}{2}\end{array}\right]$ and $T_{z p n 2 a b c}=\left[\begin{array}{ccc}1 & 1 & 1 \\ 1 & \alpha^{2} & \alpha \\ 1 & \alpha & \alpha^{2}\end{array}\right]$ are the matrix to performs the $z p n$ to $a b c$ transformation, and the $a b c$ to $\alpha \beta$ transformation respectively.

Therefore, the open-loop control of this unbalanced operation for a 1- $\phi$ connection can be illustrated in Fig. 9. With setting the complex power $\dot{S}$, the sequence network voltages on the $C_{f}$, the sequence network voltages on the converter, and the converter voltage in the $\alpha \beta$ axis are derived, and the switching signals are generated with SVPWM modulation block.

Fig. 10 shows the trajectory of the required rectifier voltage by using the technique in Fig. 9. Because the rectifier is operating in an unbalanced condition, the trajectory is not a circle but an ellipse. Because the SVPWM is applied, the 


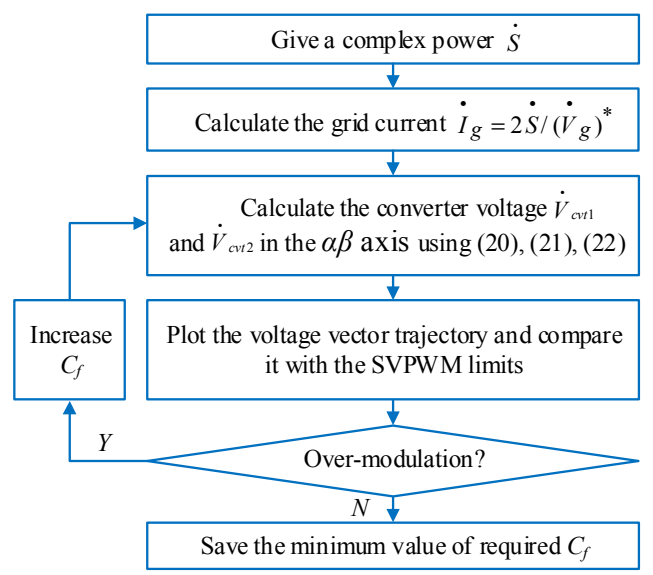

(a)

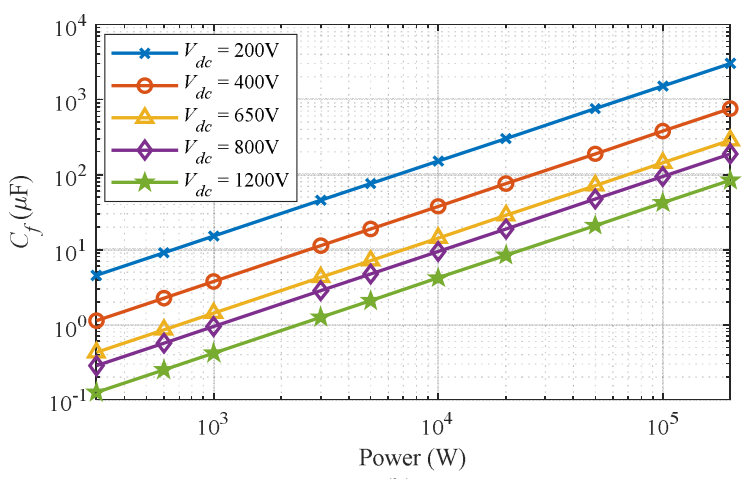

(b)

Fig. 11. The minimum $C_{f}$ with different power ratings and $V_{d c}$ (modulation index $=1$ ): (a) the flowchart of deriving the minimum $C_{f}$ and (b) the derived minimum $C_{f}$.

TABLE III

$L C L$ PARAMETERS FOR THE SYSTEM BY USING THE DESIGN TECHNIQUE IN [43]

\begin{tabular}{cccccccc}
\hline \hline $\begin{array}{c}S \\
(\mathrm{kVA})\end{array}$ & $\begin{array}{c}f_{g} \\
(\mathrm{~Hz})\end{array}$ & $\begin{array}{c}f_{s w} \\
(\mathrm{~Hz})\end{array}$ & $\begin{array}{c}V_{g} \\
(\mathrm{~V} \mathrm{rms})\end{array}$ & $\begin{array}{c}V_{d c} \\
(\mathrm{~V})\end{array}$ & $\begin{array}{c}L_{g} \\
(\mathrm{mH})\end{array}$ & $\begin{array}{c}L_{c} \\
(\mathrm{mH})\end{array}$ & $\begin{array}{c}C_{f} \\
(\mu \mathrm{F})\end{array}$ \\
\hline 200 & 60 & $20 \mathrm{k}$ & 480 & 1200 & 0.27 & 0.1 & 10 \\
10 & 50 & $50 \mathrm{k}$ & 380 & 650 & 0.336 & 0.430 & 0.95 \\
\hline \hline
\end{tabular}

modulation range is increased by $15 \%$ compared with the conventional SPWM techniques thus, without increasing the DC-link voltage, the required voltage can be fully covered with a useful margin for other possible grid connection requirements such as voltage fluctuation and reactive power provision.

\section{PARAMETER DESIGN FOR $L C L$ FILTER \& DC CAPACITOR}

\section{A. LCL Filter Design and Size/weight Evaluation}

The $L C L$ filter, as shown in Fig. 6, comprises the capacitor $C_{f}$, the grid-side inductor $L_{g}$, and the converter-side inductor $L_{c}$. Three requirements of parameters in the $L C L$ need to be met for achieving both harmonics filtering and APF functions: 1) storage of the double-frequency power pulsation $p_{100} ; 2$ ) limitation of the converter side ripple current $I_{c}$, and 3) Compliance with the grid code [42] of the grid side current $I_{g}$.

The size of $C_{f}$ is determined by the value of $p_{100}$ and the capacitor voltage. Due to unbalanced operation, the maximum voltage of the capacitor is possibly larger than the peak value of the 1- $\phi$ supply voltage.

For a fixed DC-link voltage, the capacitor maximum voltage can be located at the trajectory of the AC voltage as shown in Fig. 10. To ensure linear modulation, the elliptical trajectory of the unbalanced voltage must be within the boundary of the circular trajectory of balanced voltage. If $C_{f}$ is too small, the elliptical trajectory would exceed the circular boundary, resulting in non-linear modulation; if $C_{f}$ is too large, the modulation index would be small, so the de voltage utilization is compromised. As shown in Fig. 10, the SVPWM increases the inverted $\mathrm{AC}$ voltage by about $15 \%$ than the SPWM due to higher DC-link voltage utilization, meaning smaller $C_{f}$ when using SVPWM or additional voltage margin if the same $C_{f}$.

Fig. 11(a) shows the procedure to derive the required minimum $C_{f}$ to avoid over-modulation under the premise of satisfying eqs. (18) and (19). As shown in Fig. 11(b), $C_{f}$ increases with the increase of the power rating. The capacitance value of $C_{f}$ can be then defined by the voltage shown in Fig 10 and the power shown in Fig. 11(b).

The ripple current requirement (i.e. the requirement 2) needs the converter side inductor $L_{c}$ to satisfy the limit of the current ripple required by the converter. The equation for the inductance calculation is given in [43] and shown as (23).

$$
L_{c} \geq \frac{V_{D C}}{6 f_{s w} \Delta I_{\max }}
$$

where $f_{s w}$ is the switching frequency and the $\Delta I_{\max }$ is the maximum ripple current allowed at the converter circuit.

The grid current requirement (i.e. the requirement 3) is met by achieving the harmonics attenuation, which is calculated by using the transfer function of the $L C L$ filter. The largest grid harmonic appears when the 1- $\phi$ grid is connected (see Appendix), giving the transfer function of the $L C L$ filter for 1$\phi$ connection:

$$
G_{L C L-h a r}(s)=\frac{I_{g-h a r}(s)}{V_{c v t-h a r}(s)}=\frac{2}{s^{3} L_{g} L_{c}\left(3 C_{f}\right)+s\left(L_{g}+L_{c}\right)}
$$

Since $f_{s w}$ is much larger than the resonant frequency between the capacitor and inductor in the $L C L$ filter, then $s^{3} L_{g} L_{c} C_{f} \gg$ $s\left(L_{g}+L_{c}\right)$. Therefore, $G_{L C L}(s)$ can be simplified as (25) at $f_{s w}$ :

$$
G_{L C L-h a r}(s) \approx \frac{2}{s^{3} L_{g} L_{c}\left(3 C_{f}\right)}
$$

where $V_{\text {har }}(s)$ is the harmonic voltage of the converter, and $I_{h a r}(s)$ is the harmonic current injected to the grid.

The closed-form expressions of the switching harmonic voltages are derived in [44], showing that the most significant harmonic has the frequency $f_{s w}$. The magnitude of the most significant harmonic in a half-bridge is:

$$
V_{\text {har }}=\frac{2 V_{d c}}{\pi} J_{0}\left(\frac{\pi}{2} M\right) \leq \frac{2 V_{d c}}{\pi}
$$

where $V_{\text {har }}$ is the most significant harmonic's magnitude, $J_{0}$ is the first-order Bessel function and is always smaller than $1 ; M$ is the modulation index within $[0,1]$. When $M=0, V_{\text {har }}$ reaches its maximum value.

$$
I_{\text {har }}=V_{\text {har }} G_{L C L-h a r}\left(s=j \omega_{s w}\right) \leq I_{s t d}
$$


TABLE IV

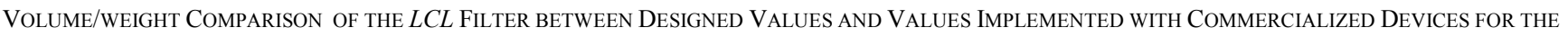
CONVENTIONAL OBC WITH $K_{C F}=1$

\begin{tabular}{|c|c|c|c|c|c|c|c|c|c|c|}
\hline & \multirow{2}{*}{$\begin{array}{l}\text { Designed } \\
\text { parameters }\end{array}$} & \multirow{2}{*}{ Selected devices } & \multicolumn{2}{|c|}{ Energy capacity (J) ${ }^{(\mathrm{r} 3)}$} & \multicolumn{2}{|c|}{$\begin{array}{c}\text { Evaluated volume } \\
(\mathrm{r} 4)\end{array}$} & \multicolumn{2}{|c|}{ Evaluated weight $(\mathrm{g})^{(\mathrm{r} 5)}$} & \multirow{2}{*}{$\begin{array}{c}\text { Actual } \\
\text { volume } \\
\left(\mathrm{mm}^{3}\right)\end{array}$} & \multirow{2}{*}{$\begin{array}{l}\text { Actual } \\
\text { weight } \\
\text { (g) }\end{array}$} \\
\hline & & & $\begin{array}{c}\text { Designed } \\
\text { parameters }\end{array}$ & $\begin{array}{c}\begin{array}{c}\text { Selected } \\
\text { devices }\end{array} \\
\end{array}$ & $\begin{array}{c}\text { Designed } \\
\text { parameters }\end{array}$ & $\begin{array}{c}\text { Selected } \\
\text { devices }\end{array}$ & $\begin{array}{c}\text { Designed } \\
\text { parameters }\end{array}$ & $\begin{array}{c}\begin{array}{c}\text { Selected } \\
\text { device }\end{array} \\
\end{array}$ & & \\
\hline$L_{c}$ & $\begin{array}{l}336 \mu \mathrm{H} \\
(a) 28 \mathrm{~A}\end{array}$ & $\begin{array}{c}7443763540470^{(\mathrm{r} 1)} \times 7 \\
(329 \mu \mathrm{H}, 31 \mathrm{~A})\end{array}$ & 0.1310 & 0.1581 & $2.62 \times 10^{5}$ & $3.16 \times 10^{5}$ & 1310 & 1720 & $3.62 \times 10^{5}$ & 1568 \\
\hline$L_{g}$ & $\begin{array}{l}430 \mu \mathrm{H} \\
\text { (a) } 28 \mathrm{~A}\end{array}$ & $\begin{array}{c}7443763540470 \times 9 \\
(423 \mu \mathrm{H}, 31 \mathrm{~A})\end{array}$ & 0.1673 & 0.2033 & $3.35 \times 10^{5}$ & $4.06 \times 10^{5}$ & 1670 & 2202 & $4.65 \times 10^{5}$ & 2016 \\
\hline$C_{f}$ & $\begin{array}{c}0.9 \mu \mathrm{F} \\
(a) 845 \mathrm{~V} \\
\end{array}$ & $\begin{array}{c}\text { MKP } 1848510094 K 2^{(\mathrm{r} 2)} \\
(1 \mu \mathrm{F}, 900 \mathrm{~V})\end{array}$ & 0.3418 & 0.4050 & 3418 & 4050 & 3.4 & 4.1 & 5472 & 6.0 \\
\hline
\end{tabular}

(r1) 7443763540470 is an inductor from Wurth Electronics Inc, and its volume/weight is $51660 \mathrm{~mm}^{3} / 224.0 \mathrm{~g}$.

(r2) $M K P 1848510094 K 2$ is a film capacitor from Vishay, and its volume/weight is $5472 \mathrm{~mm}^{3} / 6 \mathrm{~g}$.

(r3) Energy capacity equals $0.5 L I^{2}$ for inductors and $0.5 \mathrm{CV}^{2}$ for capacitors. For instances, the energy capacity of $L_{c}$ with designed parameters is $0.5 \times 336 \mu \mathrm{H}$ $\times(28 \mathrm{~A})^{2}=0.1311 \mathrm{~J}$; the energy capacity of $L_{c}$ implemented with selected devices is $0.5 \times(47 \mu \mathrm{H} \times 7) \times(31 \mathrm{~A})^{2}=0.1581 \mathrm{~J}$.

(r4) Eq. (1) shows that $V O L_{L}=$ energy capacity $/ K_{V L}$; eq. (2) shows that $V O L_{C}=$ energy capacity $/ K_{V C} . K_{V L} \approx 5 \times 10^{-7} \mathrm{~J} / \mathrm{mm}^{3}$ and $K_{V C}=1 \times 10^{-4} \mathrm{~J} / \mathrm{mm}^{3}$ can be extracted from Fig. 3.

(r5) The two coefficients $K_{W L} \approx 1 \times 10^{-4} \mathrm{~J} / \mathrm{g}$ and $K_{W C}=0.1 \mathrm{~J} / \mathrm{g}$ from Fig. 3 are used to evaluate the weight.

$$
\begin{aligned}
& \begin{array}{|l|}
\hline \multicolumn{1}{|c|}{\text { Determine the } L C L \text { parameters: }} \\
L_{c}, L_{g}, C_{f} \text {, and the maximum current and voltage } \\
\begin{array}{|l}
\text { Calculate the } \\
\text { maximum energy } \\
\text { capacity }
\end{array}
\end{array}\left\{\begin{array}{l}
E n g_{L}=\frac{1}{2} L I^{2} \\
E n g_{C}=\frac{1}{2} C V^{2}
\end{array}\right. \\
& \text { Estimate the energy density coefficient }\left(K_{V L}\right. \text {, } \\
& \left.K_{W L}, K_{V C}, K_{W C}\right) \text { from Fig. } 3 \\
& \text { Calculate the volume and weight from (1) and (2) } \\
& \left\{\begin{array} { l } 
{ V O L _ { L } = \frac { E n g _ { L } } { K _ { V L } } } \\
{ W E T _ { L } = \frac { E n g _ { L } } { K _ { W L } } }
\end{array} \quad \left\{\begin{array}{l}
V O L_{C}=\frac{E n g_{L}}{K_{V C}} \\
W E T_{C}=\frac{E n g_{L}}{K_{W C}}
\end{array}\right.\right. \\
& \begin{array}{l}
\text { Calculate the total volume and weight } \\
\left\{\begin{array}{l}
V O L_{T O T}=3\left(V O L_{C f}+V O L_{L c}+V O L_{L g}\right) \\
W E T_{T O T}=3\left(W E T_{C f}+W E T_{L g}+W E T_{L c}\right)
\end{array}\right.
\end{array}
\end{aligned}
$$

Fig. 12. The flow-chart to evaluate the volume/weight of the $L C L$ filter.

where $I_{\text {std }}$ is the maximum harmonic limit in the grid code. This paper applies IEEE Std 519 [42] as the grid limits in which $I_{\text {std }}$ $=0.3 \% I_{\text {rated }}$ when $f_{s w}>35 f_{g}$.

From (26) and (27), the minimum value of $L_{g}$ is derived as:

$$
L_{g} \geq \frac{4 V_{d c}}{\pi \omega_{s w}{ }^{3} L_{c}\left(3 C_{f}\right) I_{s t d}}
$$

Fig. 11, (23) and (28) can be used to determine $C_{f}, L_{c}$, and $L_{g}$ respectively. The proposed technique requires larger $C_{f}$ than the existing design because the value of $C_{f}$ is determined by voltage modulation and energy storage given by Fig. 10 and Fig. 11. In this paper, the DC-link voltage needs to be regulated at $650 \mathrm{~V}$ which is commonly used in OBCs and the 1- $\phi$ power rating is set to be $10 \mathrm{~kW}$, which covers the common $6.6 \mathrm{~kW}$ and $3.3 \mathrm{~kW}$ Level 2 and Level 1 charging standards.

The required $C_{f}$ is $14.3 \mu \mathrm{F}$ obtained from Fig. 11, which is larger than $0.95 \mu \mathrm{F}$ of the conventional method in [43]. However, (28) shows that the increase of $C_{f}$ can lead to a decrease of $L_{g}$. The total volume and weight of the $L C L$ filter need to be assessed.

Denoting $K_{C f}$ as the coefficient of quantifying the increase of $C_{f}$, considering $L_{c}$ remains unchanged from (23), then $L_{g}$ is decreased by $K_{C f}$ from (28). The volume and weight of the $L C L$ filter are functions of $K_{C f}$, and can be expressed as (29) and (30) respectively:

$$
\left\{\begin{array}{l}
V O L_{T O T}\left(K_{C f}\right)=3\left(K_{C f} \bullet V O L_{C f}+V O L_{L g} / K_{C f}+V O L_{L c}\right) \\
W E T_{T O T}\left(K_{C f}\right)=3\left(K_{C f} \bullet W E T_{C f}+W E T_{L g} / K_{C f}+W E T_{L c}\right)
\end{array}\right.
$$

where VOL $W E T_{L g}$, and $W E T_{L c}$ are the volume and weight of $L C L$ filter, $C_{f}$, $L_{g}$, and $L_{c}$ respectively.

In order to compare with the $L C L$ design from [43] which was for $200 \mathrm{kVA}$, the $L C L$ filter is recalculated by using the same method in [43] to compare with the filter used in this proposed method at $10 \mathrm{kVA}, 650 \mathrm{~V}$ DC-link system. The $L C L$ parameters of the conventional method in [43] at $200 \mathrm{kVA}$ and $10 \mathrm{kVA}$ are shown in TABLE III, and its volume/weight can be evaluated with Fig. 12. For the $200 \mathrm{kVA}$ system [43], $L_{c}=100 \mu \mathrm{H}, L_{g}=$ $270 \mu \mathrm{H}, C_{f}=10 \mu \mathrm{F}$; the rated current and voltage are $240 \mathrm{~A}$ (rms) and $1200 \mathrm{~V}$ (peak). If a $30 \%$ margin is used for the inductor current and capacitor voltage, the required maximum energies stored in $L_{c}, L_{g}$, and $C_{f}$ are $E n g_{L c}=0.5 L_{g}(1.3 \times \sqrt{2}$ $\times 240)^{2} \mathrm{~J}=9.78 \mathrm{~J}, \operatorname{Eng}_{L g}=0.5 L_{c}(1.3 \times \sqrt{2} \times 240)^{2} \mathrm{~J}=26.4 \mathrm{~J}$ and Eng $_{C f}=0.5 C_{f}(1.3 \times 1200)^{2}=12.2 \mathrm{~J}$. Their volume and weight can be evaluated with the energy density equation in (1). In [43], $L_{g}$ used silicon steel inductors where $K_{V L} \approx 10^{-6} \mathrm{~J} / \mathrm{mm}^{3}$ and $K_{W L} \approx$ $2 \times 10^{-4} \mathrm{~J} / \mathrm{g}$, giving $V O L_{L g}=E n g_{L c} / K_{V L}=26.4 \times 10^{6} \mathrm{~mm}^{3}$ and $W E T_{L g}==E n g_{L c} / K_{W L}=132 \times 10^{3} \mathrm{~g} ; L_{c}$ used nanocrystalline based inductor, and the volume is given as $V O L_{L c}=6.78 \times 10^{6}$ $\mathrm{mm}^{3}$ in [43], and $W E T_{L c}=V O L_{L c} /$ density $=34 \times 10^{3} \mathrm{~g}$ when density $\approx K_{V L} / K_{W L}=5.0 \mathrm{~g} / \mathrm{cm}^{3} ; C_{f}$ used film capacitors where $K_{V C} \approx 10^{-4} \mathrm{~J} / \mathrm{mm}^{3}, K_{W C} \approx 0.1 \mathrm{~J} / \mathrm{g}$, and $V O L_{C f}=121 \times 10^{3} \mathrm{~mm}^{3}$, giving $W_{E} T_{C f}=121 \mathrm{~g}$. Therefore, the total volume and weight for the system with $K_{C f}=1$ can be derived as: $V O L_{T O T}\left(K_{C f}=1\right)$ $=9.99 \times 10^{8} \mathrm{~mm}^{3} ; W T_{T O T}\left(K_{C f}=1\right)=4.98 \times 10^{5} \mathrm{~g}$. 


\section{IEEE POWER ELECTRONICS REGULAR PAPER}

From Fig. 13(a), the optimal volume can be achieved when $K_{C f}=15.25$. From (23), $L_{c}$ remains unchanged; from (29) and (30), $L_{g}$ is decreased to $\left(270 \mu \mathrm{H} / K_{C f}\right)=17.7 \mu \mathrm{H}$ and $C_{f}$ is increased to $\left(10 \mu \mathrm{F} \times K_{C f}\right)=153 \mu \mathrm{F}$. From (29) and (30), the total volume and weight are $V O L_{T O T}\left(K_{C f}=15.25\right)=3.11 \times 10^{7}$ $\mathrm{mm}^{3}$ and $W_{E T} T_{T O T}\left(K_{C f}=15.25\right)=1.33 \times 10^{5} \mathrm{~g}$, respectively. Similarly, from Fig. 13(b), the optimal weight can be achieved when $K_{C f}=31.50$. From (23), $L_{c}$ remains unchanged; from (29) and (30), $L_{g}$ is decreased to $270 \mu \mathrm{H} / K_{C f}=8.57 \mu \mathrm{H}$ and $C_{f}$ is increased to $10 \mu \mathrm{F} \times K_{C f}=315 \mu \mathrm{F}$. According to (29) and (30), the total volume and weight are $V O L_{T O T}\left(K_{C f}=15.25\right)=3.4 \times 10^{7}$ $\mathrm{mm}^{3}$ and $W E T_{T O T}\left(K_{C f}=15.25\right)=1.3 \times 10^{5} \mathrm{~g}$, respectively.

The total volume and weight of the $L C L$ filter can be plotted by using (28) and (29) as illustrated in Fig. 13. It is clearly shown that the design in [43] can be improved by increasing $K_{C f}$ so the total volume and weight of the $L C L$ filter can be decreased. The optimal $K_{C f}$ for the total volume and weight can be calculated by setting the first derivatives to be zero as

$$
\begin{gathered}
\frac{d\left(V O L_{\text {TOT }}\right)}{d K_{\text {VOL }}}=0 \text { and } \frac{d\left(W E T_{\text {TOT }}\right)}{d K_{\text {VOL }}}=0 . \text { The solutions are: } \\
\left\{\begin{array}{l}
\left.K_{C f}\right|_{\text {opt vol }}=\sqrt{\frac{V O L_{L g}}{V O L_{C f}}} \\
\left.K_{C f}\right|_{\text {opt wet }}=\sqrt{\frac{W E T_{L g}}{W E T_{C f}}}
\end{array}\right.
\end{gathered}
$$

where $\left.K_{C f}\right|_{\text {opt vol }}$ and $\left.K_{C f}\right|_{\text {opt wet }}$ are the $K_{C f}$ for the optimal volume and the optimal weight respectively.

When (31) is met, $K_{C f} V O L_{C f}=V O L_{L g} / K_{C f}$, which means that the when $C_{f}$ and $L_{g}$ have the same volume, the optimal volume can be reached. Similarly, when the $C_{f}$ and $L_{g}$ have the same weight, (32) is met and the optimal weight can be reached. In the conventional design, both the volume and weight of $L_{g}$ is much larger than $C_{f}$ due to a small capacitance of $C_{f}$. However, in this proposed design, the increased capacitance $C_{f}$ will enable the volume and weight of the $C_{f}$ and $L_{g}$ become closer to each other, thus the total volume and weight of the filter will become closer to the optimum.

For $S=10 \mathrm{kVA}$ with the $L C L$ designed technique in [43], the parameters can be derived as the marker 4 of Fig. 13(c): $L_{c}, L_{g}$, and $C_{f}$ are $336 \mu \mathrm{H}$ at $21.5 \mathrm{~A}, 420 \mu \mathrm{H}$ at $21.5 \mathrm{~A}$ and $0.96 \mu \mathrm{F}$ at $650 \mathrm{~V}$, respectively. If a $30 \%$ margin is used for the inductor current and capacitor voltage, the currents for both $L_{c}$ and $L_{g}$ are $28.0 \mathrm{~A}$, and the voltage for $C_{f}$ is $845 \mathrm{~V}$. Thus, the energy stored in $L_{c}, L_{g}$, and $C_{f}$ are $E_{n g_{L c}}=0.5 \times 336 \mu \times 28^{2}=0.1311 \mathrm{~J}$, Eng $_{L g}$ $=0.5 \times 336 \mu \times 28^{2}=0.1673 \mathrm{~J}$, and $E g_{C F}=0.5 \times 0.9 \mu \times 845^{2}=$ $0.3418 \mathrm{~J}$, respectively. If both $L_{c}$ and $L_{g}$ use inductors with MPP cores with $K_{V L} \approx 5 \times 10^{-7} \mathrm{~J} / \mathrm{mm}^{3}$, and $K_{W L} \approx 1 \times 10^{-4} \mathrm{~J} / \mathrm{g}$ as shown in Fig 1, the volume and weight are of inductors are: $V O L_{L c}=$ $2.62 \times 10^{5} \mathrm{~mm}^{3}, W E T_{L c}=1.31 \times 10^{3} \mathrm{~g}, V O L_{L g}=3.34 \times 10^{5} \mathrm{~mm}^{3}$, $W E T_{L g}=1.67 \times 10^{3} \mathrm{~g}$. For $C_{f}, K_{V C}=1 \times 10^{-4} \mathrm{~J} / \mathrm{mm}^{3}, K_{W C}=0.1 \mathrm{~J} / \mathrm{g}$, $E_{n} g_{C f}=0.5 C V^{2}=0.3418 \mathrm{~J}$, therefore, $V O L_{C f}=E n g_{C f} / K_{V C}=$ $0.3418 / 1 \times 10^{-4}=3.42 \times 10^{3} \mathrm{~mm}^{3}$, and $W E T_{C f}=E n g_{C f} / K_{W C}=$ $0.3418 / 0.1=3.42 \mathrm{~g}$.

To verify the designed effectiveness of the designed value, TABLE IV is added to compare the weight and volume between

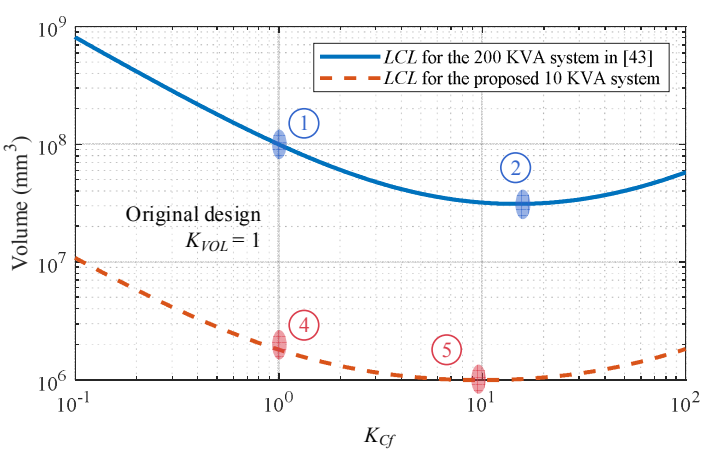

(a)

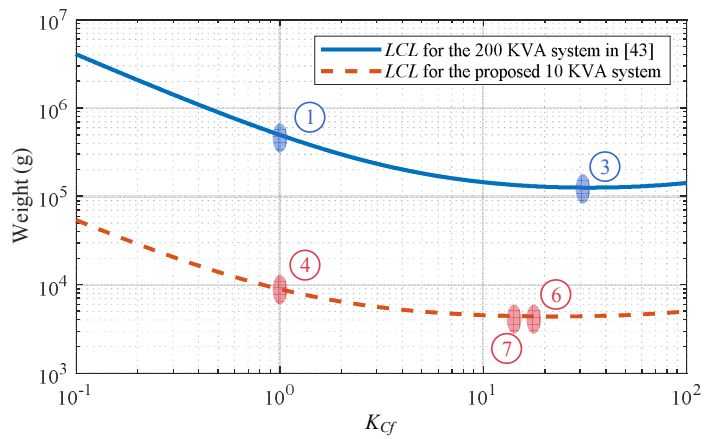

\begin{tabular}{|c|c|c|c|c|c|c|c|}
\hline \multirow[b]{2}{*}{ Marker } & \multicolumn{3}{|c|}{ System in [43] } & \multicolumn{4}{|c|}{ The proposed system } \\
\hline & (1) & (2) & (3) & (4) & (5) & (6) & (7) \\
\hline Comment & $\begin{array}{c}\text { Existing } \\
\text { value in } \\
\text { [43] }\end{array}$ & $\begin{array}{l}\text { Optimal } \\
\text { Volume }\end{array}$ & $\begin{array}{l}\text { Optimal } \\
\text { Weight }\end{array}$ & $\begin{array}{c}\text { Value } \\
\text { based } \\
{[43]}\end{array}$ & $\begin{array}{l}\text { Optimal } \\
\text { Volume }\end{array}$ & $\begin{array}{l}\text { Optimal } \\
\text { Weight }\end{array}$ & $\begin{array}{c}p_{\text {loo }}: C_{f}= \\
16 \mu \mathrm{F}\end{array}$ \\
\hline$K_{C f}$ & 1.00 & 15.25 & 31.50 & 1.00 & 10.28 & 22.93 & 16.67 \\
\hline $\begin{array}{l}V O L_{T O T} \\
\left(\mathrm{~mm}^{3}\right)\end{array}$ & $9.99 \times 10^{8}$ & $3.11 \times 10^{7}$ & $3.4 \times 10^{7}$ & $1.80 \times 10^{6}$ & $9.90 \times 10^{5}$ & $1.07 \times 10^{6}$ & $1.02 \times 10^{6}$ \\
\hline $\begin{array}{c}W E T_{T O T} \\
(\mathrm{~g})\end{array}$ & $4.98 \times 10^{5}$ & $1.33 \times 10^{5}$ & $1.3 \times 10^{5}$ & 8964 & 4528 & 4388 & 4406 \\
\hline$L_{c}(\mu \mathrm{H})$ & 100 & 100 & 100 & 336 & 336 & 336 & 336 \\
\hline$L_{g}(\mu \mathrm{H})$ & 270 & 17.7 & 8.57 & 430 & 41.8 & 18.8 & 25.8 \\
\hline$C_{f}(\mu \mathrm{F})$ & 10 & 153 & 315 & 0.96 & 9.89 & 22 & 16 \\
\hline
\end{tabular}

(b)

Fig. 13. The total (a) volume and (b) weight of the $L C L$ filter versus $K_{C f}$, and (c) the specific parameters from the above figures. The blue curves / markers / data are for the $200 \mathrm{kVA}$ system in [43]; the red curves / markers / data are for the 10 kVA system.

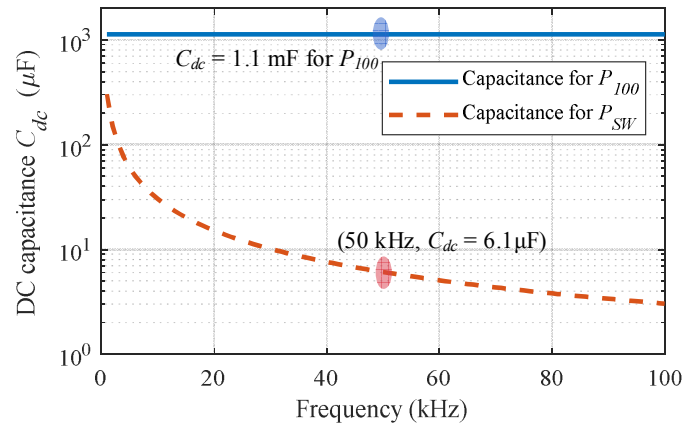

Fig. 14. The required DC capacitance comparison between $p_{100}$ and $P_{S W} . P_{d c}=3$ $\mathrm{kW}, V_{d c}=650 \mathrm{~V}, \Delta V_{d c}=13 \mathrm{~V}\left(2 \%\right.$ of $\left.V_{d c}\right)$.

the designed parameters and the commercial devices. The evaluated volume and weight are $1.8 \times 10^{6} \mathrm{~mm}^{3}$ and $8.95 \times 10^{3} \mathrm{~g}$; the volume and weight of actual commercial components are $1.8 \times 10^{6} \mathrm{~mm}^{3}$ and $8.95 \times 10^{3} \mathrm{~g}$. The differences between evaluation and actual devices are small as shown in Table IV . It should be noted that the weight and volume differences on 
the capacitor $C_{f}$ between evaluation and actual device are more significant than that from the inductors. However, the capacitor is much smaller and lighter than the inductor thus this deviation between evaluation and actual commercial components can be neglected in the $L C L$ filter design.

Fig. 13 clearly shows that volume and weight can be decreased with increased $K_{C f}$. The $L C L$ filter reaches the optimal volume and weight when $K_{C f}=10.28$ and 22.93 respectively. If $C_{f}$ is set as $16 \mu \mathrm{F}$ in this proposed method, then $K_{C f}=16.67, V_{\text {VOL }}$ TOT $=1.02 \times 10^{6} \mathrm{~mm}^{3}$ and ${ }^{W E} T_{T O T}=4406 \mathrm{~g}$, which are closer to the optimum. The volume and weight of the $L C L$ filter with $K_{C f}=16.67$ (the marker 7 in Fig. 13) can be reduced by $76.47 \%$ and $103.4 \%$ respectively compared to the conventional design with $K_{C f}=1$ (the marker 4 in Fig. 13).

In conclusion, although the proposed technique requires that the $L C L$ filter not only attenuates the harmonic current to the grid but also store the double-line frequency power pulsation, both the size/weight of the $L C L$ filter can be reduced with the proposed technique because the increased capacitance $C_{f}$ for storage has moved the total volume and weight closer to the optimum as shown in Fig. 13.

\section{B. Parameter Design for the DC-Link Capacitor}

For the conventional 1- $\phi$ HB converter, the capacitance required to smooth the $100 \mathrm{~Hz}$ power pulsation is given as [45]:

$$
C_{d c}>\frac{P_{d c}}{\left(2 \omega_{g}\right) V_{d c}\left(\frac{1}{2} \Delta V_{d c}\right)}=\frac{P_{d c}}{\omega_{g} V_{d c} \Delta V_{d c}}
$$

The proposed APF technique can eliminate the double-line frequency power pulsation. Therefore, the switching harmonics determine the DC capacitance.

The closed-form expressions of the switching harmonic voltages in [44] show that the most significant harmonics locates at the switching frequency $f_{s w}$. The magnitude of the most significant harmonic is:

$$
V_{s w}=\frac{2 V_{d c}}{\pi} J_{0}\left(\frac{\pi}{2} M\right) \leq \frac{2 V_{d c}}{\pi}
$$

where $J_{0}$ is the Bessel function of the first kind, and $M$ is the modulation index. When $M=0, V_{S W}$ reaches its maximum value.

If the AC output voltage and current are: $v_{s w}(t)=$ $V_{s w} \sin \left(\omega_{s w} t+\theta_{s w u}\right)$ and $i_{s w}(t)=I_{s w} \sin \left(\omega_{s w} t+\theta_{s w i}\right)$, where $\theta_{s w u}$ and $\theta_{s w i}$ are the initial phase of $v_{s w}(t)$ and $i_{s w}(t)$. The instantaneous

power at the AC output is $p(t)=\left(V_{g} \sin \left(\omega_{g} t\right)+\right.$ $\left.V_{s w} \sin \left(\omega_{s w} t+\theta_{s w u}\right)\right) \times\left(I_{g} \sin \left(\omega_{g} t\right)+I_{s w} \sin \left(\omega_{s w} t+\theta_{s w i}\right)\right)$. Because $I_{s w}$ needs to be smaller than $4 \%$ of the grid current $I_{g}$ to comply with the grid code [42], it can be neglected. Therefore, the expression of $p_{s w}(t)$ and its magnitude $P_{S W}$ are:

$$
\left\{\begin{array}{l}
p_{s w}(t) \approx V_{s w} I_{g} \sin \left(\omega_{g} t\right) \sin \left(\omega_{s w} t+\theta_{s w u}\right) \\
P_{S W}=\frac{1}{2} V_{s w} I_{g}
\end{array}\right.
$$

Because the semiconductors do not store energy, $P_{S W}$ also donates the magnitude of the instantaneous power at the DClink. The $P_{S W}$ for an unbalanced 3- $\phi$ converter is three times
TABLE V

CIRCUIT PARAMETERS

\begin{tabular}{cc}
\hline \hline Grid voltage $V_{g}$ & $230 \mathrm{~V}(\mathrm{RMS}, 1-\phi)$ \\
Grid frequency $f_{g}$ & $400 \mathrm{~V}(\mathrm{RMS}, 3-\phi)$ \\
Grid side inductor $L_{g}$ & $30 \mathrm{~Hz}$ \\
Converter side inductor $L_{c}$ & $350 \mu \mathrm{H}$ \\
$L C L$ capacitor $C_{f}$ & $16 \mu \mathrm{F}$ \\
DC-link capacitor $C_{d c}$ & $10 \mu \mathrm{F}$ \\
DC-link voltage $V_{d c}$ & $650 \mathrm{~V}$ \\
Output power $P_{o}$ & $3 \mathrm{~kW}(1-\mathrm{ph})$ \\
& $10 \mathrm{~kW}(3-\mathrm{ph})$ \\
Switching frequency $f_{s w}$ & $50 \mathrm{kHz}$ \\
\hline \hline
\end{tabular}
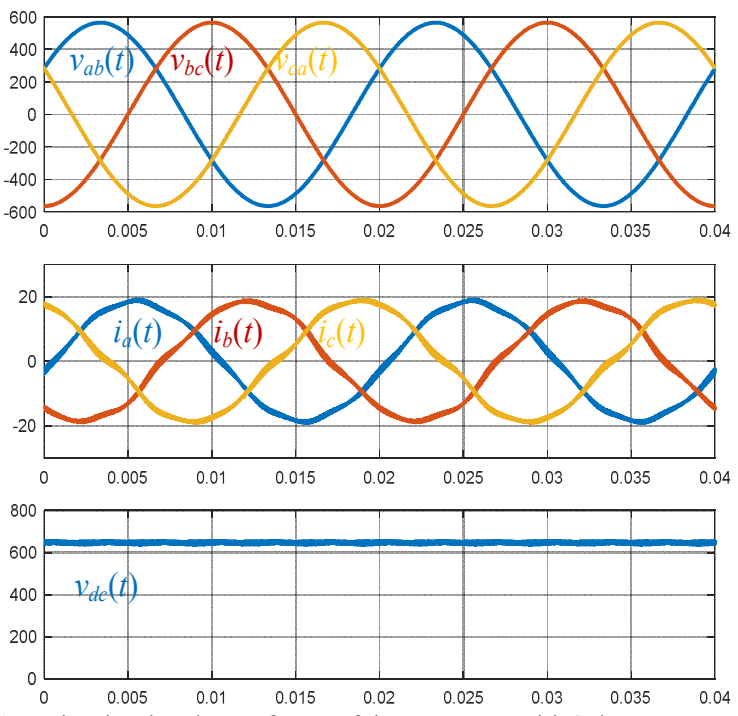

Fig. 15. The simulated waveforms of the converter with 3- $\phi$ power supply at $400 \mathrm{~V}$ and $10 \mathrm{~kW}$. The $V_{d c}=650 \mathrm{~V}$.

smaller than that in a half-bridge. The required capacitance needs to meet:

$$
C_{d c}>\frac{3 P_{s w}}{\omega_{s w} V_{d c}\left(\frac{1}{2} \Delta V_{d c}\right)}=\frac{6 P_{s w}}{\omega_{s w} V_{d c} \Delta V_{d c}}
$$

Fig. 14 shows the comparison of the required DC capacitance for the $P_{S W}$ at switching frequency and for the $p_{100}$ at the doubleline frequency. The $C_{d c}$ for $P_{S W}$ is significantly smaller than the $C_{d c}$ for $p_{100}$, especially for the applications with a large $f_{s w}$. Because the proposed technique only needs $C_{d c}$ for $P_{S W}$, the size and volume can be greatly reduced. For $f_{s w}=50 \mathrm{kHz}, C_{d c} \geq 6.1$ $\mu \mathrm{F}$, and a $10 \mu \mathrm{F}$ capacitor is used for $C_{d c}$ in this paper.

\section{SIMULATION AND EXPERIMENT RESULTS}

\section{A. Simulations}

The proposed circuit is shown in Fig. 6, and the parameters are shown in TABLE V. Fig. 15 and Fig. 16 shows the simulation results of the rectifier fed by $1-\phi$ supply at $3 \mathrm{~kW}$ and $3-\phi$ supply at $10 \mathrm{~kW}$ respectively. The proposed $\mathrm{OBC}$ will have two connectors, the 1- $\phi$ connector (regulated by BS13363) and the 3- $\phi$ connector (regulated by IEC 62196), for users to select. 

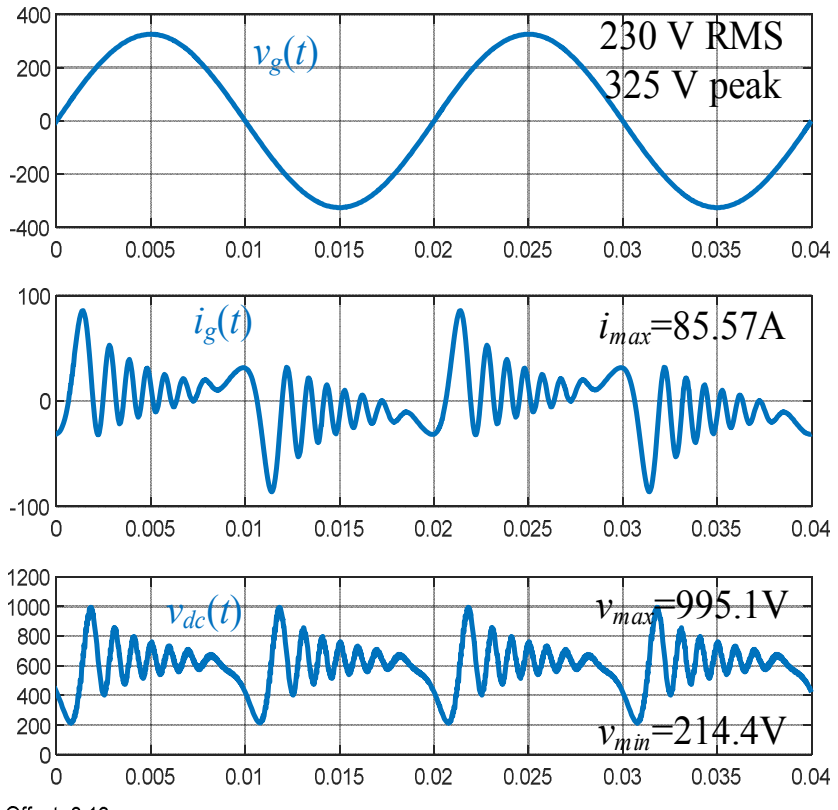

(a)
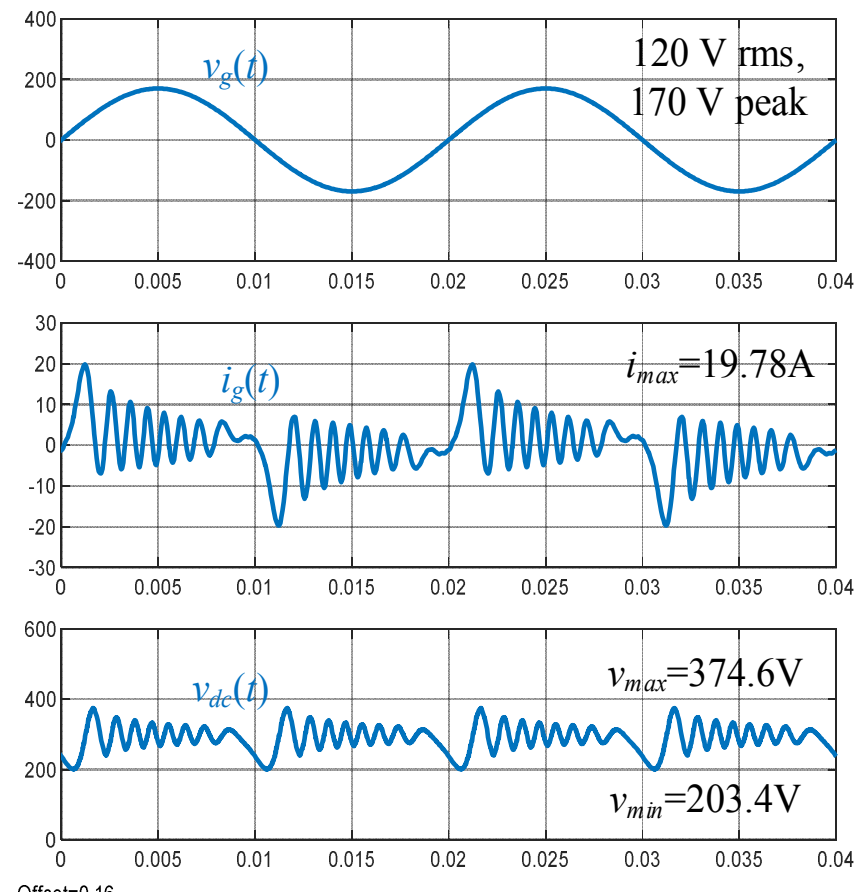

(b)

Fig. 16. The simulated waveforms of the conventional H-bridge (HB) with the $L C L$ filter (all the parameters are as shown in TABLE V) connected to a 1- $\phi$ grid: (a) $V_{g}=230 \mathrm{~V}, P_{o}=3 \mathrm{~kW}$ and (b) $V_{g}=120 \mathrm{~V}, P_{o}=300 \mathrm{~W}$.

Once the corresponding plug has been connected, the $\mathrm{OBC}$ will work accordingly for that connection, either $1-\phi$ or $3-\phi$. It is obvious that the charging voltage remains the same during each charging event, either 1- $\phi$ or 3- $\phi$ for each charging event thus there is no need for dynamic switching between 1- $\phi$ and 3- $\phi$ within one charging event. However, the additional 3- $\phi$ charging opportunity offered by the technology reported in this paper will benefit motorists by using 3- $\phi$ charging facility for
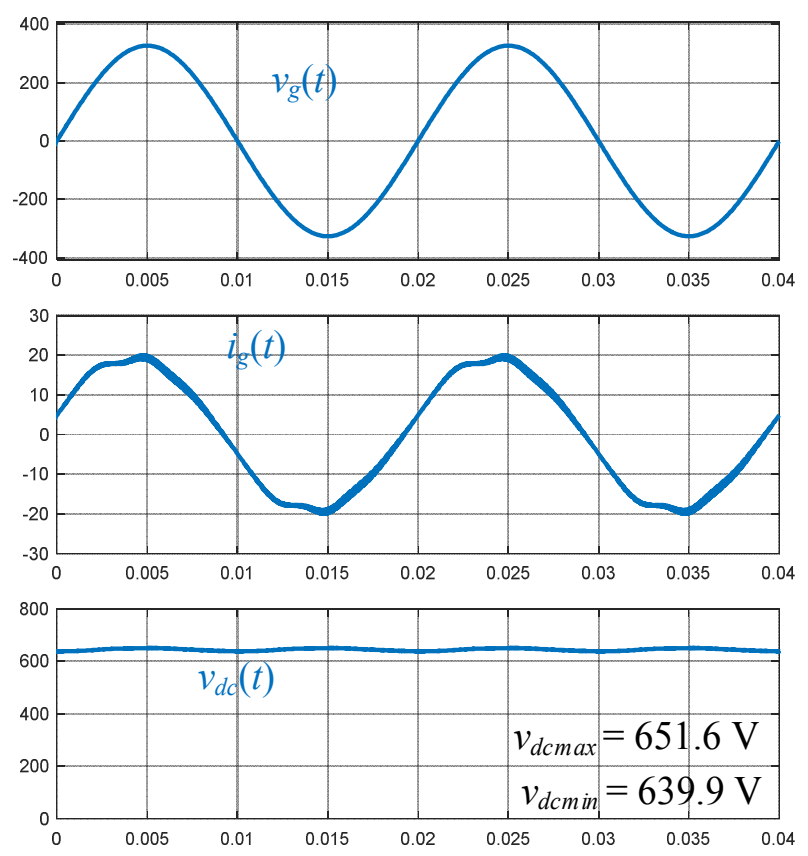

Offset $=0.08$

Fig. 17. The simulated waveforms of the proposed method of the converter connected to a $1-\phi$ grid.

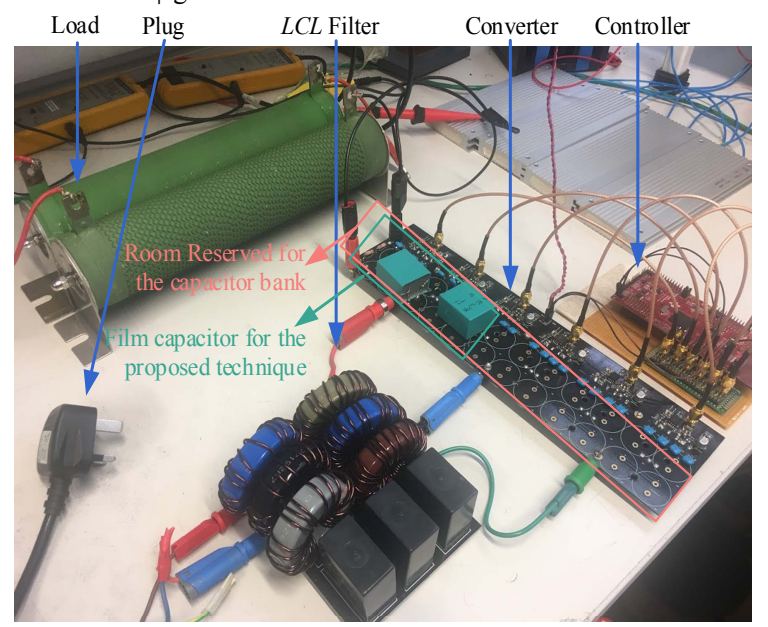

(a)

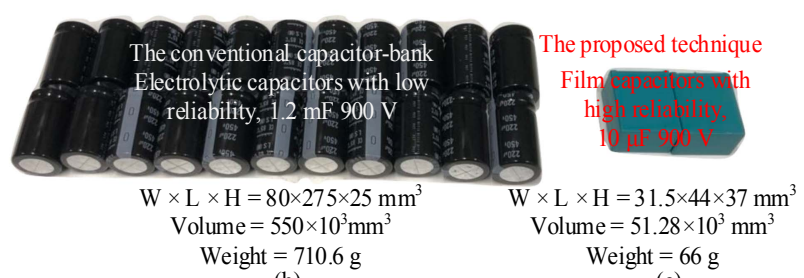

(b)

(c)

Fig. 18. Test set-up of (a) overall converter, (b) the capacitor bank for the dc capacitor storage technique, and (c) the film capacitor for the proposed technique.

three times higher charging rate by using the 1- $\phi$ and $3-\phi$ compatible OBC.

Fig. 15 shows that both the DC-link voltage and the AC line current are smooth when connected with a 3- $\phi$ grid. The performance of the rectifier with a small DC capacitor and without using the APF is firstly assessed to highlight the significance of the distortion caused by the double-line power 


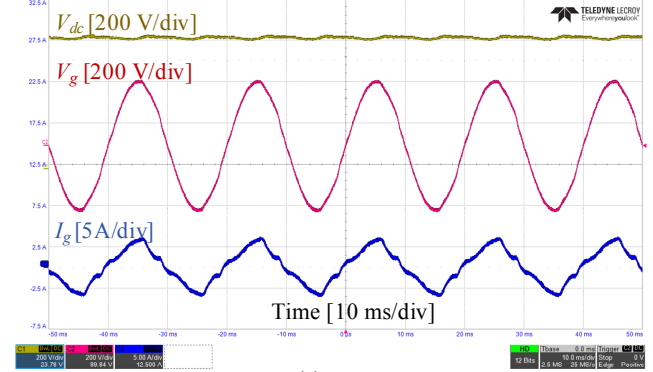

(a)

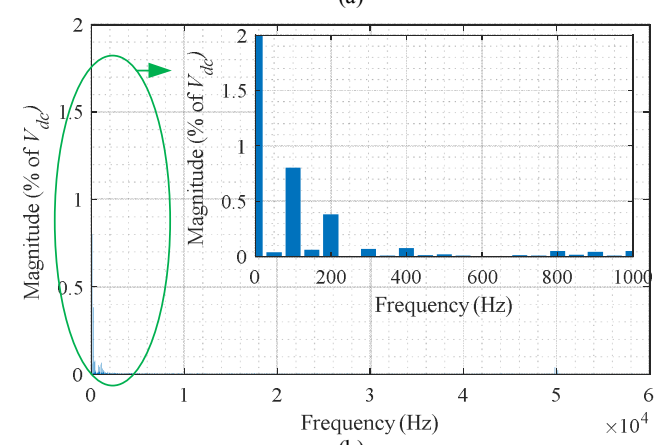

(b)

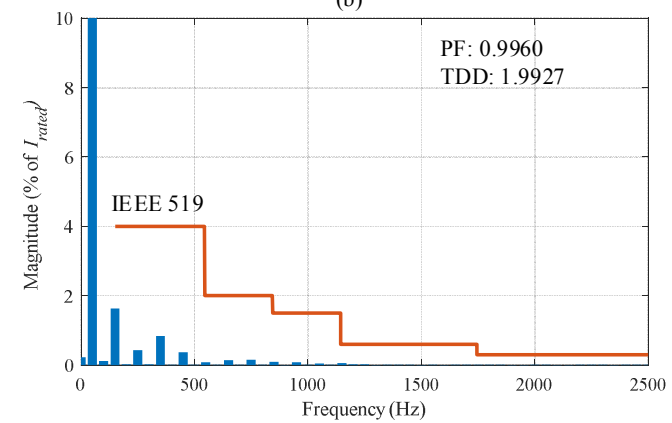

(c)

Fig. 19. The $300 \mathrm{~W}$ experimental results of the proposed technique with the 10 $\mu \mathrm{F}$ dc capacitor: (a) the waveforms of $V_{d c}, V_{g}$, and $I_{g}$, (b) the spectrum of the dc voltage $V_{d c}$, and (c) the spectrum of the grid current $I_{g}$ versus the IEEE 519 current limit.

pulsation. When connected with a 1- $\phi$ grid using the conventional 1- $\phi$ converter (the HB circuit with the $L C L$ filter in TABLE $\mathrm{V}, 10 \mu \mathrm{F}$ dc capacitor, and the SPWM modulation technique) for the rated $3 \mathrm{~kW}$ operation, as shown in Fig. 16 (a), both the DC voltage and the AC current are greatly distorted due to the $100 \mathrm{~Hz}$ power pulsation. The voltage ripple is 780.7 $\mathrm{V}$ which was more than the nominal DC voltage of $650 \mathrm{~V}$, and the maximum value reaches $95.1 \mathrm{~V}$. The grid current is also significantly distorted because of the DC voltage ripple. Because the voltage and current stress are significantly higher than th e nominal voltage and current and the magnitude of the over current and voltage depend on the power, it is impractical to verify the results with experiment at the rated power if using the same rating of the devices in the rectifier. Instead, a scaleddown test set-up with $V_{g}=120 \mathrm{~V}$ and $P_{o}=300 \mathrm{~W}$ is conducted experimentally thus a $300 \mathrm{~W}$ simulation as shown in Fig. 16(b) is also presented for comparison. If the proposed technique with $C_{d c}=10 \mu \mathrm{F}$ is applied, the DC-link voltage ripple in Fig. 17 is $11.7 \mathrm{~V}$; in comparison, if the conventional HB with $C_{d c}=10 \mu \mathrm{F}$ is applied, the ripple voltage as shown in Fig. 16(b) is (995.1-
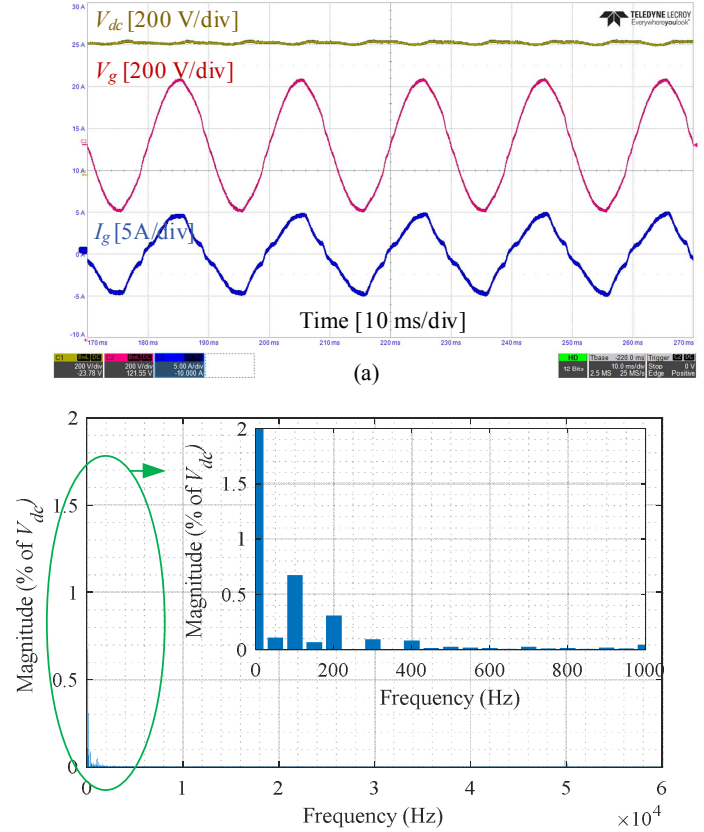

(b)

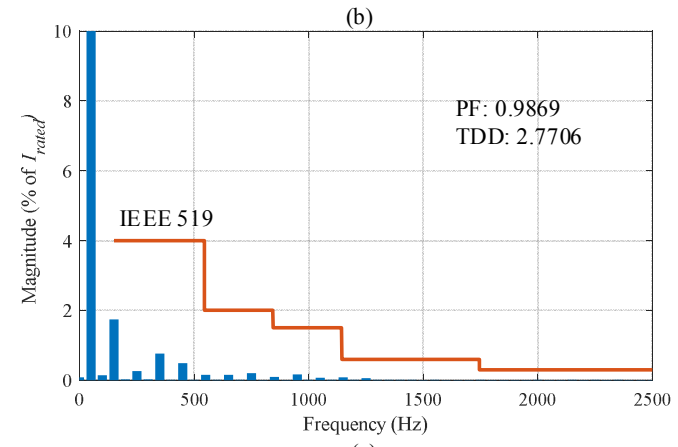

(c)

Fig. 20. The $500 \mathrm{~W}$ experimental results of the proposed technique with $10 \mu \mathrm{F}$ dc capacitors: (a) waveforms, (b) dc voltage spectrum, and (c) current spectrum versus standard limit.

214.4) $\mathrm{V}=780.7 \mathrm{~V}$. The comparison between Fig. 16(b) and Fig. 17 shows that the proposed technique can greatly reduce the $2^{\text {nd }}$ order harmonic in the DC-link. The conventional HB can also achieve small $2^{\text {nd }}$ harmonic with bulk DC capacitors, and the required $C_{d c}$ can be calculated by using (33): to achieve $\Delta V_{d c}$ $=11.7 \mathrm{~V}$, the required $C_{d c}$ is $C_{d c}=3000 /(314 \times 650 \times 11.7) \mathrm{F}=$ $1.13 \mathrm{mF}$; in comparison, to achieve $\Delta V_{d c}=11.7 \mathrm{~V}$, Fig. 17 with the proposed technique only uses $C_{d c}=10 \mu \mathrm{F}$. Comparing between $10 \mu \mathrm{F}$ in the proposed technique and the $1.13 \mathrm{mF}$ in the conventional H-bridge converter, it can be concluded that the proposed APF requires only less than 1\% capacitance of the DC capacitor to achieve the same $2^{\text {nd }}$ order DC harmonics.

\section{B. Experiments}

The experiment test set-up is shown in Fig. 18. The comparison between Fig. 18 (b) and (c) showed that the size reduction of the DC-link capacitor is significant. The significant reduction of the DC capacitance allows using the film capacitors at the DC-link, which improved the reliability and lifetime of the $\mathrm{OBC}$ due to higher robustness of the film capacitor than its electrolytic counterpart. 


\section{IEEE POWER ELECTRONICS REGULAR PAPER}
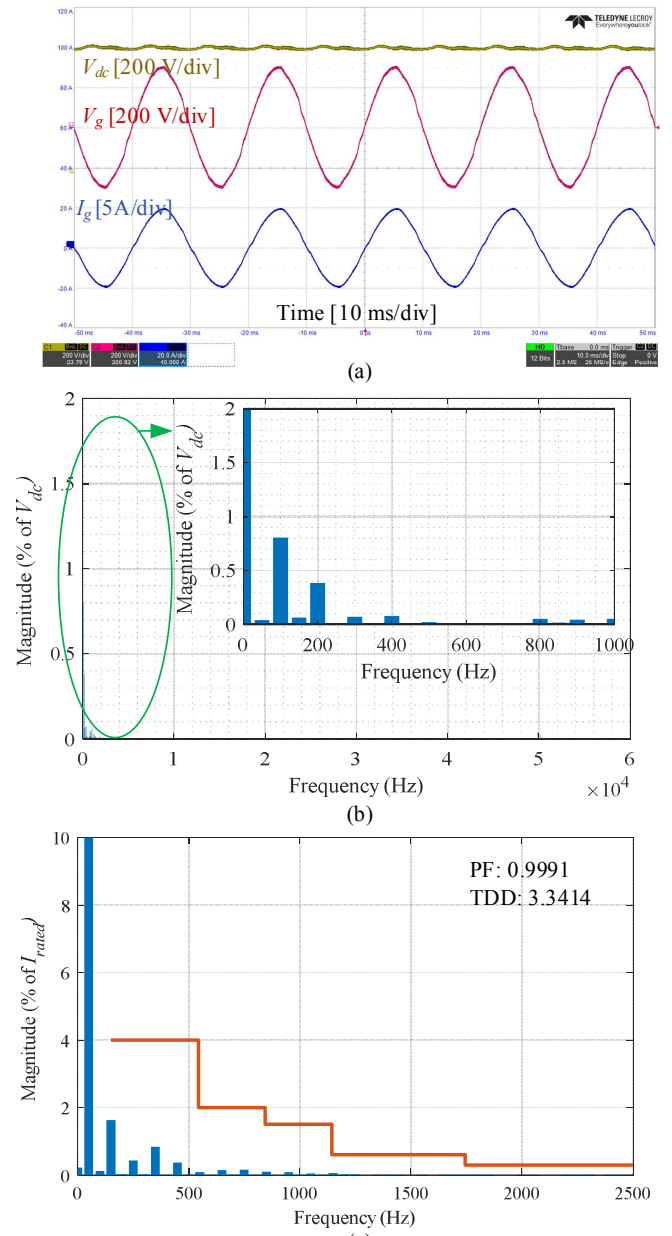

(c)

Fig. 21. The $3000 \mathrm{~W}$ experimental results of the proposed technique with the $10 \mu \mathrm{F} \mathrm{dc}$ capacitor: (a) the waveforms of $V_{d c}, V_{g}$, and $I_{g}$, (b) the spectrum of the dc voltage $V_{d c}$, and (c) the spectrum of the grid current $I_{g}$ versus the IEEE 519 current limit.

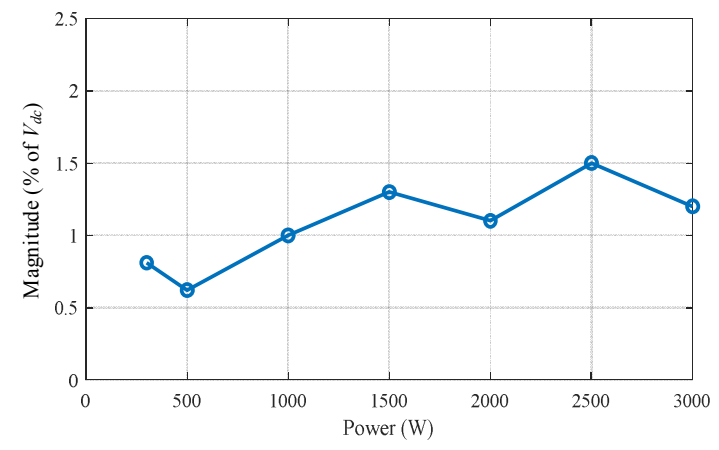

Fig. 22. The percentage of the $100 \mathrm{~Hz}$ voltage ripple of $V_{d c}$ over its mean value at various loads with the proposed technique and $10 \mu \mathrm{F}$ dc capacitor.

Fig. 19-Fig. 21 show the experiments with the proposed APF technique at $300 \mathrm{~W}, 500 \mathrm{~W}$, and $3 \mathrm{~kW}$ rated power respectively. The waveforms in Fig. 19(a), Fig. 20(a) and Fig. 21(a) show that the DC-link voltage was smooth, and the grid current is sinusoidal with acceptable small distortions; the dc ripple spectrum in Fig. 19(b), Fig. 20(b), and Fig. 21(b) show that the $100 \mathrm{~Hz}$ voltage pulsations are small at various load conditions; the grid current spectrum show that at various load conditions,

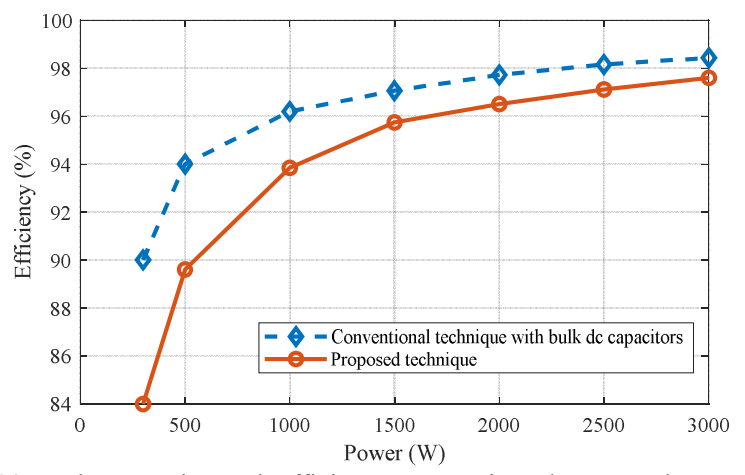

Fig. 23. The experimental efficiency comparison between the proposed technique with $10 \mu \mathrm{F}$ dc capacitor and the conventional 1- $\phi \mathrm{HB}$ converter with $1.3 \mathrm{mF}$ dc capacitor at various loads.
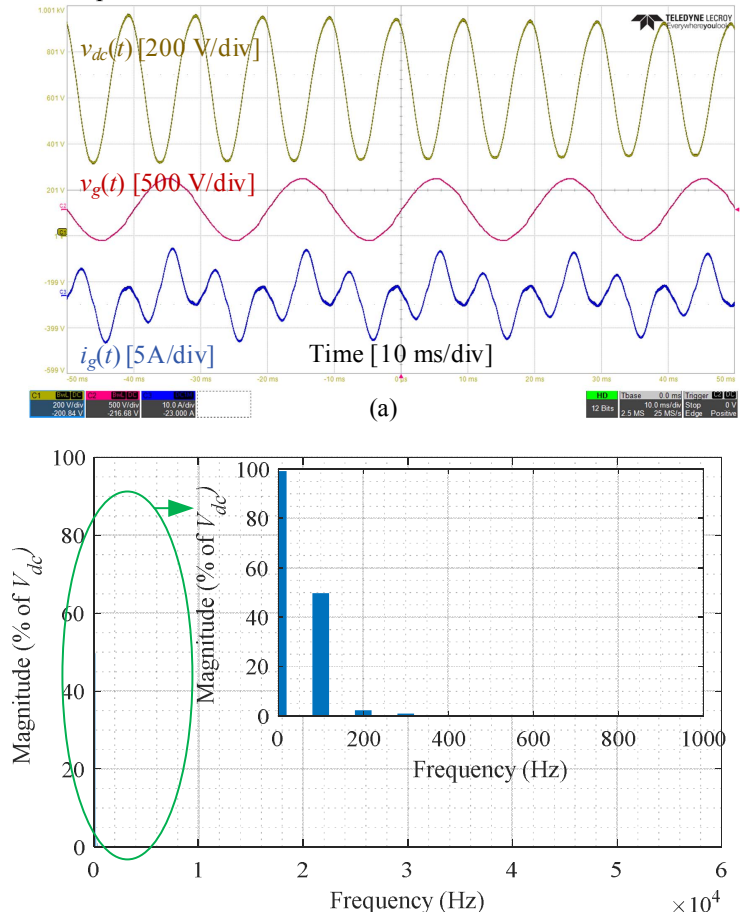

(b)

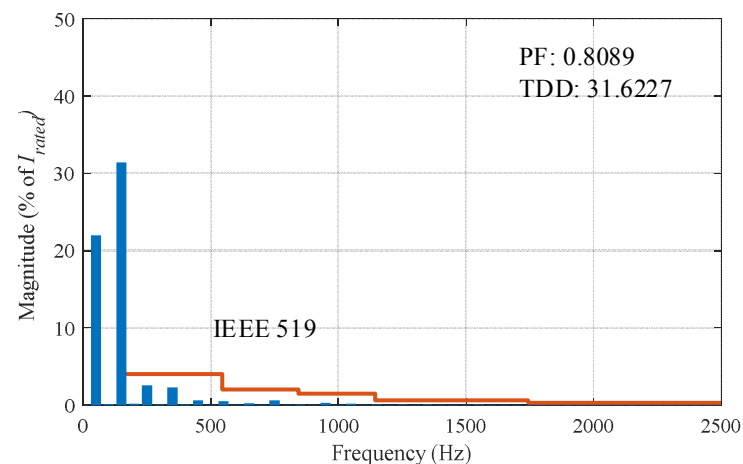

(c)

Fig. 24. The $300 \mathrm{~W}$ experimental results of the conventional H-bridge converter with the $10 \mu \mathrm{F}$ dc capacitor: (a) the waveforms of $V_{d c}, V_{g}$, and $I_{g}$, (b) the spectrum of the dc voltage $V_{d c}$, and (c) the spectrum of the grid current $I_{g}$ versus the IEEE 519 current limit.

the grid current can satisfy the grid code in the IEEE 519. The experimental results in Fig. 21 match the simulations shown in Fig. 17 well. Fig. 22 shows that the proposed technique can 

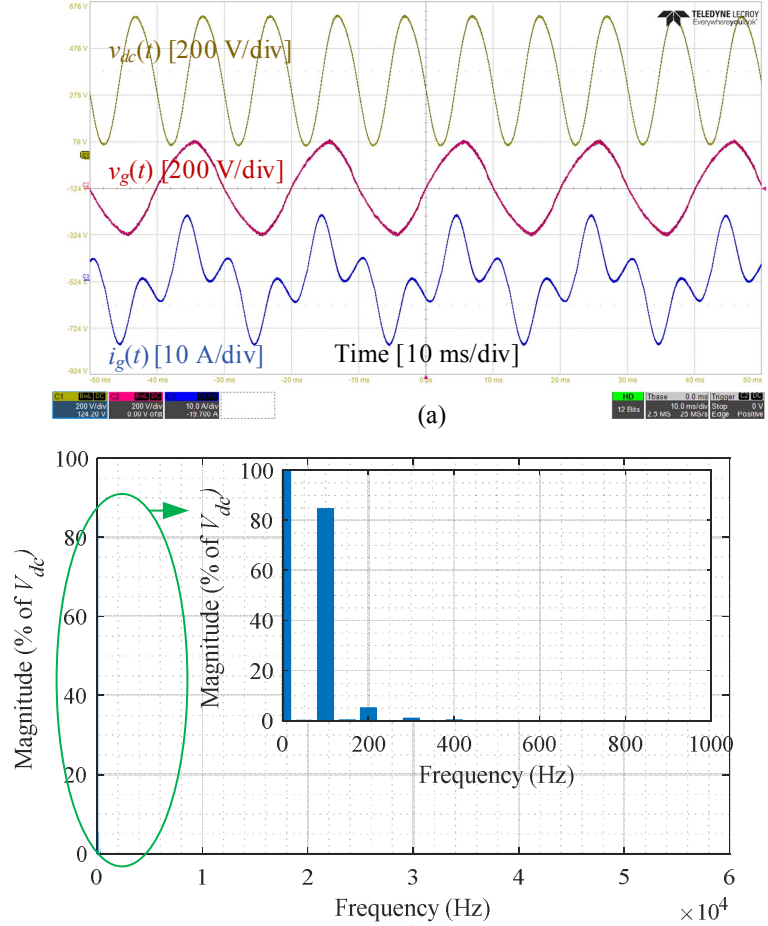

(b)

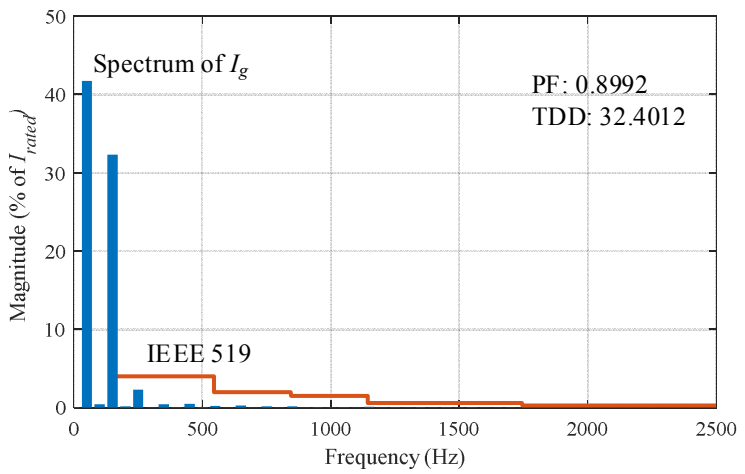

(c)

Fig. 25. The $500 \mathrm{~W}$ experimental results of the conventional H-bridge converter with the $10 \mu \mathrm{F}$ dc capacitor: (a) the waveforms of $V_{d c}, V_{g}$, and $I_{g}$, (b) the spectrum of the dc voltage $V_{d c}$, and (c) the spectrum of the grid current $I_{g}$ versus the IEEE 519 current limit.

limit the magnitude of the $100 \mathrm{~Hz}$ voltage ripple with the various loads to less than $1.5 \%$ of the DC voltage $(650 \mathrm{~V})$ from $300 \mathrm{~W}$ to $3000 \mathrm{~W}$.

Fig. 23 shows the efficiency comparison between the proposed technique with $10 \mu \mathrm{F}$ dc capacitor and the conventional 1- $\phi$ converter (the HB circuit with the $L C L$ filter in TABLE V, and the SPWM modulation technique) with 1.3 $\mathrm{mF} \mathrm{dc}$ capacitors. The efficiency of the proposed technique decreases because the extra APF (the third leg) consumes power, and the peak efficiency is $97.6 \%$ at $3000 \mathrm{~W}$.

Fig. 24(a) and Fig. 25(a) shows that the conventional 1- $\phi$ converter (which is a $\mathrm{HB}$ with the $L C L$ filter) with $10 \mu \mathrm{F} \mathrm{dc}$ capacitance suffered great distortion from both the DC-link voltage and the grid current. When operating at $500 \mathrm{~W}$, the experiment of non-APF is conducted with reduced $V_{g}(120 \mathrm{~V})$ and $V_{d c}(325 \mathrm{~V})$ to avoid the over voltage / current failure caused by power pulsation. Fig. 24(b) and Fig. 25 (b) shows that the $100 \mathrm{~Hz}$ ripple was $49.97 \%(324.8 \mathrm{~V})$ and $84.89 \%(275.8 \mathrm{~V})$ respectively. The experiment matched the simulations shown in Fig. 16 (b) well.

\section{CONCLUSION}

This paper proposes a voltage-source converter which is compatible with both 1- $\phi$ and 3- $\phi$ grids. The circuit is still the classic 3- $\phi$ converter, but the control stratagem and the $L C L$ filter are redesigned to address the issue of the power pulsation at double-line the grid frequency. When connected with a 1- $\phi$ grid, the power pulsation at double-line the grid frequency is diverted and stored into the $L C L$ filter by utilizing the third leg of the rectifier circuit. Therefore, neither extra active switches nor passive components are required. The advantages of the proposed technology can be summarized as below:

1. Good compatibility: the charger can work with both 3- $\phi$ and 1- $\phi$ grids without changing the topology. When connected with a 1- $\phi$ grid, the third leg is used, and no extra active switches are required.

2. Simple circuit: $C_{f}$ in the $L C L$ filter is utilized to store the pulsating power. $L_{g}$ and $L_{c}$ are utilized to damp the ripple current. Therefore, no extra passive components are required.

3. $L C L$ filter's size/volume reduction: Although the $C_{f}$ of the $L C L$ filter is increased to store the pulsating power, the total volume and weight of the $L C L$ filter can be reduced by $76.47 \%$ and $103.4 \%$ due to the reduction of the $L_{g}$.

4. DC-link capacitance reduction: The DC-link capacitance can be reduced by 130 times at the same switching frequency of the rectifier compared with the conventional DC capacitor storage techniques as mentioned in the experimental section.

5. Unified equations for size evaluation: the unified equations are obtained to identify the optimal circuit for AC/DC APFs with capacitors/inductors as energy storage devices and can be used to optimize the size/weight of the $L C L$ filter.

6. High dc-voltage utilization: when connected with a 1- $\phi$ grid, the system operates in an unbalanced 3- $\phi$ condition. Therefore, the advantages of the 3- $\phi$ system can be utilized to increase the DC voltage utilization by $15 \%$ and increase the utilization of the $L C L$ capacitor by three times because of applying the SVPWM and $\mathrm{Y} / \Delta$ transformation provided by the 3- $\phi$ systems.

\section{APPENDIX \\ GRID HARMONIC CURRENT WITH 1-Ф GRID}

When operating with under 1- $\phi$ voltage, the circuit is as shown in Fig. 26, which is a 4-node network. Write the nodal equations in the matrix format as follows:

$$
\boldsymbol{Y}\left[\begin{array}{l}
V_{1} \\
V_{2} \\
V_{3}
\end{array}\right]=Y_{L c}\left[\begin{array}{l}
V_{c v t a} \\
V_{c v t b} \\
V_{c v t c}
\end{array}\right]
$$




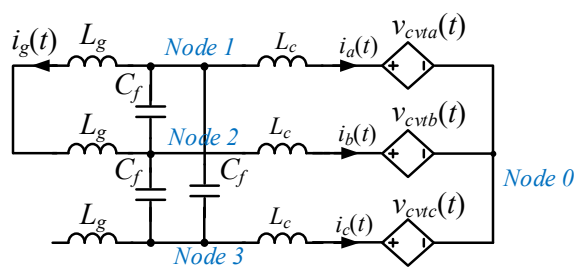

Fig. 26. The equivalent circuit of proposed technique for 1- $\phi$ grid.

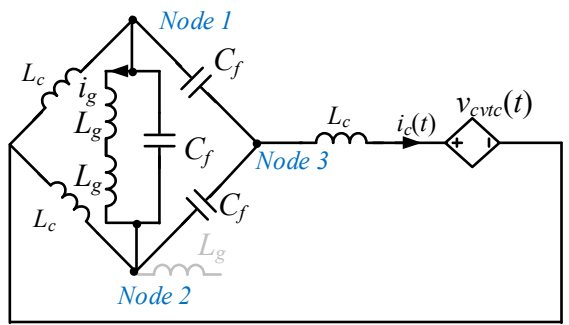

Fig. 27. The equivalent circuit when only $v_{\text {cvtc }}$ exists.

where $\boldsymbol{Y}$ is the bus admittance matrix and its value is:

$$
\boldsymbol{Y}=\left[\begin{array}{ccc}
Y_{L c}+\left(0.5 Y_{L g}+Y_{C f}\right)+Y_{C f} & -\left(0.5 Y_{L g}+Y_{C f}\right) & -Y_{C f} \\
-\left(0.5 Y_{L g}+Y_{C f}\right) & Y_{L c}+Y_{C f}+\left(0.5 Y_{L g}+Y_{C f}\right) & -Y_{C f} \\
-Y_{C f} & -Y_{C f} & Y_{L c}+Y_{C f}+Y_{C f}
\end{array}\right]
$$

where $Y_{L g}, Y_{L c}$, and $Y_{C f}$ are the admittance of $L_{g}, L_{c}$, and $C_{f}$ respectively.

Because $I_{g}=\left(V_{1}-V_{2}\right) /\left(2 s L_{g}\right), I_{g}$ can be derived in the matrix format as:

$$
I_{g}=\frac{1}{2 s L_{g}}\left[\begin{array}{lll}
1 & -1 & 0
\end{array}\right]\left[\begin{array}{c}
V_{1} \\
V_{2} \\
V_{3}
\end{array}\right]=\frac{1}{2 s L_{g}}\left[\begin{array}{lll}
1 & -1 & 0
\end{array}\right] \boldsymbol{Y}^{-1} Y_{L c}\left[\begin{array}{c}
V_{1} \\
V_{2} \\
V_{3}
\end{array}\right] \text {, and }
$$

can be simplified as:

$$
I_{g}=\frac{V_{c v t a}-V_{c v t b}}{s^{3} L_{g} L_{c}\left(3 C_{f}\right)+s\left(L_{g}+L_{c}\right)}
$$

Because the most significant harmonic is $V_{\text {har }}$, and $V_{\text {cvta }} \leq V_{\text {har }}$, $V_{c v t b} \leq V_{\text {har }}$. The maximum value of $I_{g}$ is as (38),

$$
I_{g-h a r} \leq \frac{2 V_{h a r}}{s^{3} L_{g} L_{c}\left(3 C_{f}\right)+s\left(L_{g}+L_{c}\right)}
$$

Define $G_{L C L-h a r}$ as the maximum harmonic transfer function, then,

$$
G_{L C L-h a r}=\frac{I_{g-h a r}}{V_{c v t-h a r}}=\frac{2}{s^{3} L_{g} L_{c}\left(3 C_{f}\right)+s\left(L_{g}+L_{c}\right)}
$$

With a balanced 3- $\phi$ system, the transfer function of the $L C L$ filter is $G_{L C L-h a r}=\frac{1}{s^{3} L_{g} L_{c}\left(3 C_{f}\right)+s\left(L_{g}+L_{c}\right)}$, and the maximum voltage harmonic remains unchanged as (26). Therefore, the worst scenario for $I_{g}$ harmonics happens when connected to a 1- $\phi$ grid, and the LCL filter designed for the proposed 1- $\phi$ system can meet the grid current harmonic for the balanced 3- $\phi$ system.

Eq. (37) shows that $V_{\text {cvtc }}$ has no contribution to $I_{g}$. To analyse the reason, the superposition theory is applied. Thus, all the voltage sources except $V_{\text {cvtc }}$ are shorted as shown in Fig. 27. It is seen that Node 1 and Node 2 are in the equal voltage potential points of a balanced Wheatstone bridge when the only $v_{c v t c}$ is applied. Therefore, $I_{g}$ is independent of $V_{\text {cvtc }}$.

\section{REFERENCES}

[1] D. Varajão, R. E. Araújo, L. M. Miranda, and J. A. P. Lopes, "Modulation Strategy for a Single-Stage Bidirectional and Isolated AC-DC Matrix Converter for Energy Storage Systems," IEEE Trans. Ind. Electron., vol. 65, no. 4, pp. 3458-3468, Apr 2018.

[2] X. Wang, C. Jiang, B. Lei, H. Teng, H. K. Bai, and J. L. Kirtley, "PowerLoss Analysis and Efficiency Maximization of a Silicon-Carbide MOSFET-Based Three-Phase 10-kW Bidirectional EV Charger Using Variable-DC-Bus Control," IEEE J. Emerg. Sel. Topics Power Electron., vol. 4, no. 3, pp. 880-892, Jun 2016

[3] D. B. W. Abeywardana, P. Acuna, B. Hredzak, R. P. Aguilera, and V. G. Agelidis, "1- $\phi$ Boost Inverter-Based Electric Vehicle Charger With Integrated Vehicle to Grid Reactive Power Compensation," IEEE Trans. Power Electron., vol. 33, no. 4, pp. 3462-3471, Apr 2018.

[4] D. Cesiel and C. Zhu, "A Closer Look at the On-Board Charger: The development of the second-generation module for the Chevrolet Volt," IEEE Electrific. Mag., vol. 5, no. 1, pp. 36-42, Mar 2017.

[5] International Energy Agency, "Global EV Outlook 2018," May 2018. Available: https://webstore.iea.org/global-ev-outlook-2018

[6] M. Yilmaz and P. T. Krein, "Review of Battery Charger Topologies, Charging Power Levels, and Infrastructure for Plug-In Electric and Hybrid Vehicles," IEEE Trans. Power Electron., vol. 28, no. 5, pp. 21512169, Aug 2013.

[7] U.S. DRIVE Department of Energy, "Electrical and Electronics Technical Team Roadmap," October $2017 . \quad$ Available: https://www.energy.gov/sites/prod/files/2017/11/f39/EETT\%20Roadma $\mathrm{p} \% 2010-27-17 . p d f$

[8] Automotive Council UK, "The Roadmap Report - Towards 2040: A Guide to Automotive Propulsion Technologies," Jun 2018. Available: https://www.apcuk.co.uk/app/uploads/2018/06/roadmap-report-26-618.pdf

[9] Electric Vehicle and Plug-in Hybrid Electric Vehicle Conductive Charge Coupler, SAE J1772 2017-10, 2017.

[10] Plugs, socket-outlets, vehicle connectors, and vehicle inlets - Conductive charging of electric vehicles - Part 1: General requirements, IEC 62196 2014-06, 2014.

[11] J. Ye, C. Shi, and A. Khaligh, "1- $\phi$ Charging Operation of a Three-Phase Integrated Onboard Charger for Electric Vehicles," in Proc. IEEE ITEC, 2018, pp. 681-686.

[12] K. Yoo, K. Kim, and J. Lee, "Single- and Three-Phase PHEV Onboard Battery Charger Using Small Link Capacitor," IEEE Trans. Ind. Electron., vol. 60, no. 8, pp. 3136-3144, Jun 2013.

[13] H. B. Li, K. Zhang, H. Zhao, S. F. Fan, and J. Xiong, "Active Power Decoupling for High-Power 1- $\phi$ PWM Rectifiers," IEEE Trans. Power Electron., vol. 28, no. 3, pp. 1308-1319, Mar 2013.

[14] L. Xue, Z. Shen, D. Boroyevich, P. Mattavelli, and D. Diaz, "Dual Active Bridge-Based Battery Charger for Plug-in Hybrid Electric Vehicle With Charging Current Containing Low Frequency Ripple," IEEE Trans. Power Electron., vol. 30, no. 12, pp. 7299-7307, Mar 2015.

[15] T. Kim et al., "Analytical study on the low-frequency ripple effect of battery charging," in Proc. IEEE VPPC, Feb 2012, pp. 809-811.

[16] H. Z. Z. Beh, G. A. Covic, and J. T. Boys, "Effects of pulse and DC charging on lithium iron phosphate (LiFePO4) batteries," in Proc. IEEE ECCE, 2013, pp. 315-320.

[17] S. Cho, I. Lee, J. Baek, and G. Moon, "Battery Impedance Analysis Considering DC Component in Sinusoidal Ripple-Current Charging," IEEE Trans. Ind. Electron., vol. 63, no. 3, pp. 1561-1573, Mar 2016.

[18] H. Ouyang, K. Zhang, P. Zhang, Y. Kang, and J. Xiong, "Repetitive Compensation of Fluctuating DC-Link Voltage for Railway Traction Drives," Power Electronics, IEEE Transactions on, vol. 26, no. 8, pp. 2160-2171, Jan 2011

[19] L. Y, Yanxiao, K. Wang, L. Zhao, Q. Ge, Z. Li, and Y. Li, "An Improved Torque and Current Pulsation Suppression Method for Railway Traction Drives Under Fluctuating DC-Link Voltage," IEEE Trans. Power Electron., vol. 33, no. 10, pp. 8565-8577, Nov 2018. 


\section{IEEE POWER ELECTRONICS REGULAR PAPER}

[20] H. Zhao, H. Li, C. Min, and K. Zhang, "A modified 1- $\phi$ h-bridge PWM rectifier with power decoupling," in Proc. IEEE IECON, 2012, pp. 80-85.

[21] W. Yao, P. C. Loh, Y. Tang, X. Wang, X. Zhang, and F. Blaabjerg, "A Robust DC-Split-Capacitor Power Decoupling Scheme for 1- $\phi$ Converter," IEEE Trans. Power Electron., vol. 32, no. 11, pp. 8419-8433, 2017.

[22] Y. Xia, J. Roy, and R. Ayyanar, "A Capacitance-Minimized, Doubly Grounded Transformer less Photovoltaic Inverter With Inherent ActivePower Decoupling," IEEE Trans. Power Electron., vol. 32, no. 7, pp. 5188-5201, 2017.

[23] M. A. Vitorino, L. F. S. Alves, R. Wang, and M. B. d. R. Corrêa, "LowFrequency Power Decoupling in 1- $\phi$ Applications: A Comprehensive Overview," IEEE Trans. Power Electron., vol. 32, no. 4, pp. 2892-2912, 2017.

[24] T. Shimizu, T. Fujita, G. Kimura, and J. Hirose, "A unity power factor PWM rectifier with DC ripple compensation," IEEE Trans. Ind. Electron., vol. 44, no. 4, pp. 447-455, 1997.

[25] Y. Liu, Y. Sun, M. Su, M. Zhou, Q. Zhu, and X. Li, "A 1- $\phi$ PFC Rectifier With Wide Output Voltage and Low-Frequency Ripple Power Decoupling," IEEE Trans. Power Electron., vol. 33, no. 6, pp. 5076-5086, 2018.

[26] S. Li, W. Qi, S. Tan, and S. Y. R. Hui, "A Single-Stage Two-Switch PFC Rectifier With Wide Output Voltage Range and Automatic AC Ripple Power Decoupling," IEEE Trans. Power Electron., vol. 32, no. 9, pp. 6971-6982, 2017.

[27] H. B. Li, K. Zhang, and H. Zhao, "DC-Link Active Power Filter for HighPower 1- $\phi$ PWM Converters," J. of Power Electron., vol. 12, no. 3, pp. 458-467, May 2012.

[28] B. Ge et al., "An Active Filter Method to Eliminate DC-Side LowFrequency Power for 1- $\phi$ Quasi-Z Source Inverter," IEEE Trans. Ind. Electron., vol. 63, no. 8, pp. 1-1, Aug 2016.

[29] B. Ge et al., "Direct Instantaneous Ripple Power Predictive Control for Active Ripple Decoupling of 1- $\phi$ Inverter," IEEE Trans. Ind. Electron., vol. 65, no. 4, pp. 3165-3175, Apr 2018.

[30] P. Fang, B. Sheng, W. Sam, Y. Zhang, and Y. Liu, "LED Driver Achieves Electrolytic Capacitor-Less and Flicker-Free Operation with an Energy Buffer Unit," IEEE Trans. Power Electron., pp. 1-1, 2018.

[31] S. Fan, Y. Xue, and K. Zhang, "A novel active power decoupling method for 1- $\phi$ photovoltaic or energy storage applications," in Proc. IEEE ECCE, 2012, pp. 2439-2446.

[32] Y. Tang, D. Zhu, C. Jin, P. Wang, and F. Blaabjerg, "A Three-Level Quasi-Two-Stage 1- $\phi$ PFC Converter with Flexible Output Voltage and Improved Conversion Efficiency," IEEE Trans. Power Electron., vol. 30, no. 2, pp. 717-726, 2015.

[33] Hammond Manufacturing, "Transformers \& Inductors," Transformer and Inductor $\quad$ catalog, $2018 . \quad$ Available: http://www.hammondmfg.com/pdf/5C08.pdf

[34] Magnetics Inc, "Magnetics Powerder Core Catalog," 2017. Available: https://www.mag-inc.com/Media/Magnetics/FileLibrary/Product\%20Literature/Powder\%20Core\%20Literature/2017Magnetics-Powder-Core-Catalog.pdf

[35] Shang Sung Corp, "Magnetic Powder Cores Catalog," 2015. Available: http://eu0707.cafe24.com/ eng/download/mgnetic powder cores.pdf

[36] KEMET, "C4AE Capacitor, Radial, 2 or 4 Leads, 450-1100 Vdc," 2018.

[37] Vishay, "Metallized Polypropylene Film Capacitors DC-Link Capacitor," 2018. https://content.kemet.com/datasheets/KEM F3046 C4AE RADIAL.pdf

[38] TDK, "Metallized Polypropylene Film Capacitors (MKP)," 2018. Available: https://www.tdkelectronics.tdk.com/inf/20/20/db/fc_2009/MKP_B32774_778.pdf

[39] Magnetics Inc. (2018). Powder Core Calculations. Available: https://www.mag-inc.com/Design/Design-Guides/Powder-CoreCalculations

[40] R. Wang et al., "A High Power Density 1- $\phi$ PWM Rectifier With Active Ripple Energy Storage," IEEE Trans. Power Electron., vol. 26, no. 5, pp. 1430-1443, 2011.

[41] Y. Liu, Y. Sun, M. Su, X. Li, and S. Ning, "A Single Phase AC/DC/AC Converter With Unified Ripple Power Decoupling," IEEE Trans. Power Electron., vol. 33, no. 4, pp. 3204-3217, 2018.

[42] IEEE Recommended Practice and Requirements for Harmonic Control in Electric Power Systems, 2014.
[43] Y. Jiao and F. C. Lee, "LCL Filter Design and Inductor Current Ripple Analysis for a Three-Level NPC Grid Interface Converter," IEEE Trans. Power Electron., vol. 30, no. 9, pp. 4659-4668, 2015.

[44] D. G. Holmes and T. A. Lipo, Pulse Width Modulation for Power Converters: Principles and Practice. John Wiley \& Sons, 2003.

[45] Cree, "6.6 kW BI-DIRECTIONAL EV ON-BOARD CHARGER," 2018. Available: https://www.wolfspeed.com/media/downloads/CPWRAN25.pdf

[46] 13 A plugs, socket-outlets, adaptors and connection units. Specification for rewirable and non-rewirable 13 A fused plugs, BS 1363-1:2016, 2016 